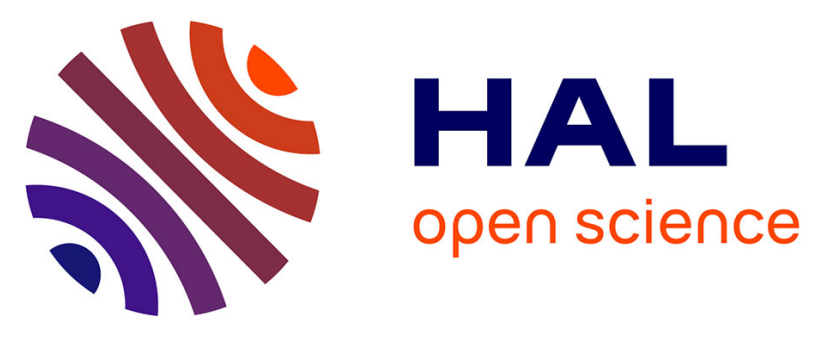

\title{
Proteomic and metabolomic profiling underlines the stage- and time-dependent effects of high temperature on grape berry metabolism
}

David Lecourieux, Christian Kappel, Stéphane Claverol, Philippe Pieri, Regina Feil, John E Lunn, Marc Bonneu, Lijun Wang, Eric Gomès, Serge

Delrot, et al.

\section{To cite this version:}

David Lecourieux, Christian Kappel, Stéphane Claverol, Philippe Pieri, Regina Feil, et al.. Proteomic and metabolomic profiling underlines the stage- and time-dependent effects of high temperature on grape berry metabolism. Journal of Integrative Plant Biology, 2020, 62 (8), pp.1132-1158. 10.1111/jipb.12894 . hal-03003936

\section{HAL Id: hal-03003936 https://hal.science/hal-03003936}

Submitted on 1 Dec 2020

HAL is a multi-disciplinary open access archive for the deposit and dissemination of scientific research documents, whether they are published or not. The documents may come from teaching and research institutions in France or abroad, or from public or private research centers.
L'archive ouverte pluridisciplinaire HAL, est destinée au dépôt et à la diffusion de documents scientifiques de niveau recherche, publiés ou non, émanant des établissements d'enseignement et de recherche français ou étrangers, des laboratoires publics ou privés. 
1 Running Title: Heat stress impacts grape berry proteome and metabolism

3 Proteomic and metabolomic profiling underlines the stage- and time4 dependent effects of high temperature on grape berry metabolism

5

6

David Lecourieux $^{1 *}$, Christian Kappel ${ }^{2}$, Stéphane Claverol $^{3}$, Philippe Pieri ${ }^{1}$, Regina Feil ${ }^{4}$, John E. Lunn ${ }^{4}$, Marc Bonneu ${ }^{3}$, Lijun Wang ${ }^{5}$, Eric Gomès ${ }^{1}$, Serge Delrot ${ }^{1}$ and Fatma Lecourieux ${ }^{6}$ 9

10

11

${ }^{1}$ UMR1287 EGFV, Université de Bordeaux, INRA, Bordeaux Sciences Agro, ISVV, 33140 Villenave

12 d'Ornon, France.

13

${ }^{2}$ Institut für Biochemie und Biologie, Universität Potsdam, D-14476 Potsdam, Germany

14

${ }^{3}$ Université de Bordeaux, Plateforme Protéome, Centre de Génomique Fonctionnelle Bordeaux, 33076

15 Bordeaux, France.

$16{ }^{4}$ Max Planck Institute of Molecular Plant Physiology, Wissenschaftspark Golm, Am Mühlenberg 1,

1714476 Potsdam-Golm, Germany

$18{ }^{5}$ Institute of Botany, Chinese Academy of Sciences, Beijing 100093, China

${ }^{6}$ UMR1287 EGFV, CNRS, Université de Bordeaux, INRA, Bordeaux Sciences Agro, ISVV, 33140

20

Villenave d'Ornon, France.

21

22

23

"Corresponding author: david.lecourieux@inra.fr 


\section{ABSTRACT}

27 Climate change scenarios predict an increase in mean air temperatures and in the frequency, intensity, 28 and length of extreme temperature events in many wine-growing regions worldwide. Because elevated 29 temperature has detrimental effects on the berry growth and composition, it threatens the economic 30 and environmental sustainability of wine production. Using Cabernet Sauvignon fruit-bearing cuttings, 31 we investigated the effects of high temperature (HT) on grapevine berries through a label-free shotgun proteomic analysis coupled to a complementary metabolomic study. Among the 2279 proteins

33 identified, 592 differentially abundant proteins were found in berries exposed to HT. The gene 34 ontology categories "Stress", "Protein", "Secondary metabolism" and "Cell wall" were predominantly 35 altered under HT. High temperatures strongly impaired carbohydrate and energy metabolism, and the 36 effects depended on the stage of development and duration of treatment. Transcript amounts correlated poorly with protein expression levels in HT berries, highlighting the value of proteomic studies in the context of heat stress. Furthermore, this work reveals that HT alters key proteins driving berry development and ripening. Finally, we provide a list of differentially abundant proteins that can be considered as potential markers for developing or selecting grape varieties that are better adapted to warmer climates or extreme heat waves. 
Grapevine is economically the most important fruit crop in the world, providing dried fruits, table grapes and the basis for wine making (www.oiv.int; www.fao.org). The combination of climate, soil and viticultural practices in a given region constitutes a highly interactive system known as "terroir" (Deloire et al. 2005). The interaction between "terroir" and the plant's genotype (cultivar) significantly affects vine development and berry composition, and thereafter determines wine quality and character (Van Leeuwen and Seguin 2006). Grapevine requires suitable temperatures, radiation intensities and duration, and water availability during the growth cycle for optimal fruit production and quality (Kuhn et al. 2014). Because of on-going climate change, the environmental parameters in most wine producing regions around the world are expected to change, potentially lowering productivity and altering the traditional characteristics ("typicity") of the wine from a given region (Schultz and Jones 2010). While some of these climatic constraints can be overcome, at least partially, by viticultural practices, temperature remains more difficult to control under field conditions (Van Leeuwen et al. 2013). Climate change scenarios predict an increase in global mean temperatures between 1.5 and $5^{\circ} \mathrm{C}$, during the $21^{\text {th }}$ century (IPCC, 2014), in addition to an increase in the frequency, intensity, and duration of extreme temperature events (Lobell et al. 2008). Considering that air temperature is a key climate variable affecting grapevine phenology, berry metabolism and composition (Jones et al. 2005; Martínez-Lüscher et al. 2016), global warming represents a serious threat for wine production and/or typicity in many wine-growing regions worldwide (Fraga et al. 2016).

Temperatures above the optimum are sensed as heat stress by living organisms. Heat stress disturbs cellular homeostasis and can lead to severe retardation in growth and development and even death (Wahid et al. 2007). In grapevine, warming promotes vegetative growth and disturbs the plant's carbon balance (Greer and Weedon 2012), adversely affecting flower set and young berry development (Greer and Weston 2010). HS also impacts fruit primary and secondary metabolism, desynchronizing sugar and organic acid metabolism and delaying sugar and polyphenol accumulation during ripening (Torregrosa et al. 2017; Gouot et al. 2018). As a consequence, heat waves occurring during key berry development stages can dramatically affect the organoleptic properties of wine even when more favourable weather conditions prevail for the remaining of the season.

In this context, the common viticultural practice of removing leaves around the fruit zone to enhance aroma development and avoid fungal infections (Alem et al. 2018), might be questioned since it affects light exposure and temperature of the berries. Because of the direct irradiative effects, temperature within the fruit may differ very significantly from that of the whole plant or surrounding air (Cola et al., 2009). The microclimate (mostly temperature and light conditions) strongly influences the metabolite composition of berries, affecting flavonols, anthocyanins, amino acids and aroma precursors (Downey et al. 2006; Pereira et al. 2006; Asproudi et al. 2016; Young et al. 2016; Reshef et al. 2017). These effects can be explained, at least in part, by the substantial remodelling of the fruit transcriptome observed under these conditions (du Plessis et al. 2017; Lecourieux et al. 2017). 
In a previous report, we showed dramatic biochemical and transcriptomic changes in heat-exposed berries, depending on both the developmental stage and the stress duration (Lecourieux et al. 2017). Although transcriptomic analyses have offered comprehensive insights into the mechanisms underlying the HS responses in grape (Liu et al. 2012; Carbonell-Bejerano et al. 2013; Rienth et al. 2014b; Jiang et al. 2017; Lecourieux et al. 2017), it is recognised that changes in transcript abundance do not always correlate with the levels of the encoded proteins (Keller and Simm 2018). Furthermore, proteins represent a more functional level of gene expression than transcripts because they have a direct impact on metabolism and other cellular processes. Therefore, state of the art mass spectrometry analysis of the proteome is a powerful tool to study molecular mechanisms and biological traits in plants, including responses to abiotic stresses (Kosova et al. 2018). Using shotgun proteomic tools such as iTRAQ (isobaric Tags for Relative and Absolute Quantitation) and label-free quantification techniques, several proteomic studies have recently investigated the heat responses of grapevine leaves (Liu et al. 2014; Jiang et al. 2017) or grape cell cultures (George et al. 2015).

To better understand the consequences of high temperature (HT), inherent to leaf removal, on berry development and to improve our knowledge about the molecular mechanisms involved in grapevine fruit response to HT, the present work combines transcriptomic, proteomic and metabolite analysis using Cabernet Sauvignon fruit-bearing cuttings. A label-free proteomic approach was used to investigate changes in the grape berry proteome resulting from direct exposure to elevated temperature. The collected proteomic data were compared with our previous transcriptomic analysis performed on the same berry samples (Lecourieux et al., 2017). These data showed a strong and negative effect of HT on proteins related to carbohydrate and energy metabolism, which led us to analyse the impact of HT on primary metabolites using tandem mass spectrometry (LC-MS/MS). Finally, we focused on proteins accumulating in berries exposed to HT that are potentially involved in thermotolerance. Altogether, this work helps to better understand the consequences of heat stress on developing grape berries and provides a list of potential heat-tolerance molecular markers that could be useful for breeders and viticulturists.

\section{RESULTS AND DISCUSSION}

\section{Quantitative analysis of heat stress responsive proteins in grape berries}

115 Experiments were performed on fruit-bearing cuttings of $V$. vinifera Cabernet Sauvignon as described 116 in Lecourieux et al. (2017). In brief, berries at three different stages of development were exposed to elevated temperatures for $12 \mathrm{~h}(7: 00 \mathrm{am}$ to 7:00 pm) during each day of treatment and harvested for

118 analysis after 1 and 7 days of treatment. The average pulp temperature of the heat-treated berries was 119 about $8^{\circ} \mathrm{C}$ higher than in control berries. A label-free proteomic approach was performed to identify 120 proteins with differential abundance between control and heat-treated berry samples.

121 Using the parameters and filters described in the Material and Methods, the conducted label-free 
experiment led to the identification of 3972 protein groups (from here on referred to as proteins) in the combined dataset from the six conditions (three stages $\mathrm{x}$ two treatment durations), of which 2279 showed two or more unique peptides (Table 1). Protein abundance changes between control and heatexposed fruits were considered to be significant when a minimum fold change of $1.5\left(\log _{2} \mathrm{FC}>0.58\right.$ or $<-0.58$ ) was reached, with a significance threshold of $p<0.05$. Only proteins identified in all three biological replicates were considered for quantification. Among the quantified proteins with a minimum of two unique peptides, 592 DAPs (differentially abundant proteins) displayed significant differences in abundance between control and HT berries in at least one of the six conditions. The entire dataset is available via ProteomeXchange (identifier PXD014693) and in Supplementary Table S1. Further information on the 592 DAPs is provided in Supplementary Table S2. Among these 592 DAPs, 501 proteins were identified in only one condition (139 up-regulated and 362 down-regulated) while the 91 remaining proteins were retrieved in more than one condition (16 up-regulated, 61 downregulated, and 14 proteins that were up-regulated in some conditions but down-regulated in others) (Table 1 and Table S2). More DAPs were identified at the ripening stage (304 DAPs) than at the green (146 DAPs) or veraison stages (222 DAPs). Whereas the numbers of up- and down-regulated proteins were similar at veraison (115 up, 107 down), more down-regulated proteins were found when the HT was applied at the green stage (24 up, 122 down) or ripening (49 up, 255 down) stages (Figure 1A). The DAPs identified after short (1 day) treatments were mostly different from those observed after long (7 days) treatments. Indeed, only 1 (up), 9 (4 up, 5 down) and 18 ( 2 up, 16 down) common DAPs between 1D or 7D of HT were observed at the green, veraison and middle ripening stages, respectively (Figure 1B and Tables S2, S3, S4 \& S5). Similarly, at all three stages, only one common down-regulated DAP was identified after 1 day of HT (VIT_12s0057g01020, fasciclin-like protein), with none being detected after 7 days of treatment (Table S2). The number of common DAPs per stage increased when looking for proteins with modified abundance after 1 and/or 7 days treatment. In this case, 7 DAPs (3 up, 4 down) were found in common for the three stages, and up to 31 DAPs were obtained when comparing heat effects between green and veraison stages (Figure 1C and Supplementary Table 2).

To determine the functional categories affected by HT, the identified DAPs were functionally classified using MapMan BIN codes (Usadel et al. 2005) and a $V$. vinifera mapping file (Lecourieux et al., 2017). The predominant proteins changed in berries in response to HT were assigned to "protein metabolism" (114/592 DAPs, 19.3\%), "stress" (54/592 DAPs, 9.1\%), "secondary metabolism" (31/592 DAPs, 5.2\%) and "cell wall" (25/592 DAPs, 4.2\%) (Figure 2). Except for the categories "stress" (36 up, 18 down) and "RNA" (10 up, 9 down), all the others categories contained more downregulated proteins that up-regulated ones, with particularly asymmetrical changes in some categories, such as "lipid metabolism" ( 0 up, 16 down) and "transport" ( 2 up, 17 down). No particular effect of HT according to the developmental stage was observed on these functional categories, whereas categories linked to carbohydrate and energy metabolism (glycolysis, tricarboxylic acid (TCA) cycle, 
fermentation, gluconeogenesis, minor and major carbohydrate (CHO) metabolism) or related to "photosynthesis", "cell wall" and "redox" were mostly impacted during veraison and/or ripening stages (Supplementary Table 2).

\section{Poor correlation between the transcriptome and proteome in heat-stressed berries}

164 Global analyses based on gene expression and protein profiles provide a powerful tool for understanding how organisms respond to environment changes. To integrate proteomic data with transcriptomic results, the present protein abundance data were compared to each corresponding differentially expressed gene (DEG) identified in the same grape berry samples exposed to HT (Lecourieux et al., 2017). Whereas 592 DAPs were retrieved in at least one of the six HT conditions (Table 1, Supplementary Table S1), 6848 DEGs were identified using the same berry samples (Lecourieux et al. 2017). A linear correlation between differentially expressed transcripts and the corresponding proteins was established for 64 out of 592 DAPs (Figure 4, Supplementary Table S11). Two types of correlation profiles were found. The first one corresponds to proteins and transcripts that exhibit profiles with the same tendency (up- or down-regulation in response to HT) and the second one includes proteins and transcripts that are inversely correlated for a same gene. The best relationship between mRNA and protein levels (39 DAPs) was observed when HT was applied for one day at veraison, and for proteins belonging to functional BINs associated to "heat stress" (25 members), "hormone" (4), and "secondary metabolism" (5) (Figure 4, Supplementary Table S11).

Our results underline the poor correlation between the proteome and the transcriptome in HT berries, with only $11 \%(64 / 592$ DAPs) of the differentially abundant proteins that were also impacted at the mRNA expression level. This is not unexpected since HT leads to denaturation and aggregation of proteins, and because translation, especially under elevated temperature, is governed by a variety of regulatory mechanisms independent of transcription rate (Bokszczanin and Fragkostefanakis 2013). These include the impacts of miRNAs on mRNA stability and translatability, mRNA half-life, global and transcript specific translational rates, as well as protein turnover. Any lag between the synthesis of a gene transcript and its translation into a protein could also give rise to an apparent discrepancy between transcript and protein abundance at a given sampling time (Keller and Simm 2018). Last but not least, the poor correlation between transcript and protein levels in heat-treated berry samples may also be due to alternative splicing (AS) events. Increasing evidence has shown that AS is a critical post-transcriptional event and plays an important role in plant stress responses (Baurle 2016). Particularly, many genes are under transcriptional regulation by the circadian clock, and several circadian clock genes show AS in response to even small changes in temperature (James et al. 2018).

192 In grapevine, AS changes were observed for nearly $70 \%$ of the genes in leaves exposed to 193 temperatures above $35^{\circ} \mathrm{C}$. In the same study, only 64 out of the 808 identified DAPs were retrieved as 194 differentially expressed at the transcript level (Jiang et al. 2017), that fits well with the weak transcript/protein correlation observed in our work. Jiang et al. (2017) suggested that AS changes 
under high temperature could provide molecular plasticity allowing the plants to adapt to stress conditions. Using Arabidopsis (Arabidopsis thaliana) plants exposed or not to a non-lethal HT, referred to as priming, Ling et al. (2018) have recently demonstrated that AS functions as a novel component of heat-shock memory.

Despite the generally poor correlation between individual transcripts and proteins levels in berries exposed to HT, there was a much better correspondence at the functional category level, with transcripts and proteins assigned to the "stress", "protein metabolism" and "secondary metabolism" MapMan BINs showing consistent responses as a group (Supplementary Figure S1). We also noticed that, at the transcript level, most of the functional categories were differentially affected according to the developmental stage and the stress duration whereas it was less obvious at the protein level. The best relationship between transcripts and proteins levels was observed with genes related to the category "stress", and especially to the "heat" sub-category. Among the 30 HSPs whose protein abundance increased in response to HT, 25 were also up-regulated at the transcript level (Supplementary Table S12). Most proteins are inherently thermo-labile, with some becoming denatured at the temperatures that grapevines experience during a heat wave. In addition, high temperature is often associated with oxidative stress leading to production of reactive oxygen species that irreversibly damage proteins. Maintaining proteins in stable and functional conformations and preventing their aggregation are essential for survival of cells under high temperature. HSPs function as molecular chaperones in maintaining protein quality and folding, and are required for the acquisition of plant thermotolerance (Bokszczanin and Fragkostefanakis 2013). It is well established that transcription factors from the HSF family regulate the heat stress response in plants, through a massive up-regulation of HSP genes (Scharf et al. 2012). However, as transcription factors are low abundance proteins they largely escaped proteomic detection, and no HSF was retrieved in the present study despite the observed transcriptional up-regulation of six $V v i H S F$ genes in heat-exposed berries (Lecourieux et al. 2017).

In good agreement with our transcriptomic data, the protein abundance of the functional category "Protein metabolism" was strongly impacted with nearly $20 \%$ of the identified DAPs that belong to this category being affected, especially those belonging to the sub-categories "protein synthesis" (34 DAPs) and "protein degradation" (55 DAPs) (Supplementary Table S6). However, the HT triggered a strong down-accumulation effect on the "protein metabolism" category (92 out of the 114 DAPs), in contrast with what was observed on transcripts (333 up- and 307 down-regulated genes). A number of studies demonstrated that different abiotic stresses, including heat, result in a general inhibition of protein translation (Yanguez et al. 2013). Accordingly, we observed a significant decrease in abundance of many proteins related to protein synthesis including various ribosome structural proteins and several translation initiation factors (Supplementary Table S6). Whereas inhibiting translation under stress helps to reduce energy consumption, certain specific mRNAs are selectively translated to produce relevant proteins involved in the proper establishment of the stress adaptation process. By 
studying the translatome of Arabidopsis seedling exposed to HT, Yanguez et al. (2013) observed that regulation of gene expression at the translational level is superimposed on regulation at the transcriptional level, and often reinforces the response of individual genes/proteins to heat stress. Protein translation is accomplished by the combined actions of the ribosomes and ancillary proteins such as initiation, elongation, and termination factors. Yanguez et al. (2013) showed that translation could be regulated at the initiation phase in Arabidopsis seedlings exposed to HT, even if the mechanisms involved in this regulation remain unclear. To date, there is some evidence for the role of different plant translation initiation factors (eIFs) in various abiotic stresses responses (Dutt et al. 2015). Our proteomic data highlighted the increase in abundance of four eIFs upon HS, namely eIF1A (VIT_15s0046g01500), two isoforms of eIF3 (VIT_14s0060g01630, VIT_00s0880g00020) and eIF5 (VIT_14s0006g01990), whereas others eIF isoforms were decreased (Supplementary Table S6). eIF5 (VIT_14s0006g01990) showed the highest accumulation score ( $\left.\log _{2} \mathrm{FC} 5.22\right)$ within this functional category. The importance of eIF5 proteins in thermotolerance was highlighted in pea (Suragani et al. 2011) and Arabidopsis (Xu et al. 2011; Zhang et al. 2017).

Heat stress alters key proteins driving berry development and ripening

\section{Heat stress impacts the secondary metabolism in developing berry}

The strong effects of HT observed on transcripts assigned to the "secondary metabolism" functional category (291 DEGs across the six conditions, (Lecourieux et al. 2017)) were confirmed at the protein level (31 out of the 592 DAPs), albeit to a lesser extent (Supplementary Table S8). These 31 DAPs (11 up, 20 down) mainly belonged to the subcategories: "isoprenoids" (7 DAPs), "phenylpropanoidlignin" (12) and "flavonoids" (7).

HT altered expression of numerous genes related to aromatic potential, including genes encoding biosynthetic enzymes for terpenes and methoxypyrazines (Lecourieux et al. 2017), but the proteomic data from the current study suggested that these changes in transcript abundance were not translated through to the protein level. A few proteins related to isoprenoid subfamily were down-accumulated under HT including a 3-ketoacyl-CoA synthase (KCS10, VIT_04s0008g02250), which is involved in the synthesis of very long chain fatty acids that are incorporated into plant lipids (precursors of cuticular waxes), and several enzymes related to the synthesis of precursors of terpenoids

263 (Supplementary Table S8). By contrast, a carotenoid cleavage dioxygenase (CCD1,

264 VIT_13s0064g00810) was found more abundant in stressed berries at veraison. Expression of various $V v C C D$ genes was reported to increase towards berry ripening and enzymes in this family were demonstrated to promote desirable flavor and aroma compounds in grapes and wine (Mathieu et al. 2005; Rienth et al. 2014a; Alem et al. 2018). The putative role of CCD proteins in heat responses is

268 still unknown but these proteins were suggested to enhance tolerance to various abiotic stresses 269 through their enzymatic products (e.g. apocarotenoids) acting as stress signals (Havaux 2014). For 
instance, some members of the CCD family are involved in generating carotenoid-derived phytohormones, such as strigolactones known to be involved in various plant developmental and adaptation processes (Jia et al. 2018).

It is well known that extreme high temperatures significantly affect the phenylpropanoid content of grape berries, with the impact being dependent on the intensity and duration of the HS as well as the developmental stage of the fruit (Gouot et al. 2018). Consistent with changes observed at the transcript level (Lecourieux et al. 2017), HT triggered an enhanced abundance of proteins involved in lignin synthesis, including shikimate O-hydroxycinnamoyltransferase (HCT; VIT_09s0018g01190), cinnamyl alcohol dehydrogenase (CAD; VIT_03s0180g00260, VIT_02s0025g03100,

279 VIT_00s0615g00030) and caffeic acid O-methyltransferase (CCoAOMT1; VIT_16s0098g00850). A 280 significant increase in lignin biosynthesis would confer additional strength to lignified secondary cell wall, helping berries to protect against shriveling mediated-HT. For instance, the activation of the lignin pathway is a reaction to advanced stages of dehydration in grape berry fruit (Zamboni et al. 2010). Key enzymes of the general phenylpropanoid pathway (phenylalanine ammonia-lyase PAL, VIT_06s0004g02620, VIT_08s0040g01710, VIT_13s0019g04460; cinnamate 4-hydroxylase C4H, VIT_06s0004g08150; 4-coumarate-CoA ligase 4CL; VIT_11s0052g01090), enzymes from the flavonoid biosynthesis pathway (dihydroflavonol 4-reductase DFR, VIT_18s0001g12800; flavonoid

288 VIT_06s0009g02860; flavanone 3'-hydroxylase F3H, VIT_18s0001g14310; isoflavone reductase, 289 VIT_03s0038g04700) as well as enzymes mediating the glycosylation of flavonoids (UDP-glucosyl transferases, VIT_12s0055g00290, VIT_02s0033g00130, VIT_17s0000g04750; UDP-rhamnosyl transferase, VIT_00s0218g00150) were also affected at the protein level upon HT. Most of these proteins were less abundant in heated berries, suggesting a sharp decline of the corresponding enzymatic activities (Supplementary Tables S2 \& S8). This lower amount of key enzymes probably contributes to the reduction of flavonoid synthesis in grape berries exposed to heat. However, other concomitant processes may explain the decrease of flavonoid contents in warmed berries, including reduced biosynthetic enzyme activities due to non-optimal temperature, enzymatic oxidation or chemical degradation after ROS scavenging (Gouot et al. 2018). Upon their biosynthesis in the cytosol, flavonoids are rapidly accumulated into vacuoles or other cellular compartments through vesicle trafficking, membrane transporters or glutathione S-transferase (GST)-mediated transport 300 (Zhao 2015). In addition to transport of flavonoids into vacuoles mediated by ATP-binding cassette 301 (ABC) transporters (Francisco et al. 2013), there is also $\mathrm{H}^{+}$-dependent transport mechanism in grapevine (Gomez et al. 2011; Kuang et al. 2019). Vacuolar transport of anthocyanins and other metabolites, such as malate, directly or indirectly depends on the transmembrane $\mathrm{pH}$ gradient

304 generated by both tonoplast $\mathrm{H}^{+}$-ATPases and $\mathrm{H}^{+}$-pyrophosphatases (V-PPase) (Shiratake and 305 Martinoia 2007). Three V-ATPase subunits (VIT_03s0038g00790, VIT_18s0001g01020, 306 VIT_04s0008g02460) and two V-PPases (VIT_11s0118g00350, VIT_09s0002g07880) showed strong 
decrease in protein abundance in HT berries, and this may impair the efficient transport of anthocyanins into the vacuole. Finally, the translational repression of several GST proteins (VIT_01s0026g01340, VIT_01s0011g01900, VIT_08s0040g03100, VIT_19s0093g00310, VIT_07s0104g01800) observed in heat-stressed berries during ripening could have an impact on fruit secondary metabolism as well (Perez-Diaz et al. 2016).

\section{Harmful effects of heat stress on carbohydrate and energy berry metabolism}

314 A drastic negative effect of HT was observed for proteins assigned to primary carbohydrate metabolism (Supplementary Table S9). Almost all the DAPs related to the following processes were under-accumulated after HT: major CHO metabolism (6 out of 8 DAPs), glycolysis (8 out of 9 DAPs), fermentation (4 out of 5 DAPs), gluconeogenesis (3 out of 4 DAPs), oxidative pentose phosphate pathway (6 DAPs) and TCA cycle (13 out of 14 DAPs). To better understand the consequences of this HT repressive effect, and to expand beyond the previously reported metabolite changes (Lecourieux et al., 2017), we measured an additional 31 metabolites that are involved in sugar or organic acid metabolism, or respiration. To put the measured metabolites into a metabolic context, a schematic representation of plant central carbon metabolism was created to display the metabolite profiles under HT compared to control conditions, for each developmental stage and each stress duration (Figure 3, Supplementary Table S10). A significant effect of the developmental stage (twoway ANOVA, $p<0.05$ ) was observed for most quantified metabolites (23 out of 31), in agreement with the previously reported metabolite profiles in developing berries from Cabernet Sauvignon fruitbearing cuttings (Dai et al. 2013). HT significantly influenced the content of 14 metabolites including shikimate, glycerate, glycerol-3-P (G-3-P), several glycolytic intermediates (fructose 6-phosphate (Fru6P), 3-phosphoglycerate (3-PGA) and pyruvate), fumarate, and several sugar phosphates (glucose 6-P (G6P), trehalose 6-P (T6P), sucrose 6'-P (S6P) and mannose 6-P (M6P)). The well-known accelerated decrease of malate under elevated temperature was also observed although the changes were below the level of significance in an ANOVA test. However, when considered over the 14-day time frame of the experiments, the decrease in malate was statistically significant according to a t-test (Figure 3). This agrees with the significantly lower malate content detected previously in HT berries at harvest (Lecourieux et al., 2017).

Metabolism undergoes profound reprogramming during fleshy fruit development (Beauvoit et al. 2018). The contents of primary and secondary metabolites have been investigated in developing grape berries (Dai et al. 2013; Degu et al. 2014; Cuadros-Inostroza et al. 2016; Wang et al. 2017). Using Cabernet Sauvignon fruit-bearing cuttings as in the present work, Dai et al. (2013) conducted a deep analysis of metabolites from central carbon metabolism using an LC-MS/MS approach. They reported the timing of important switches in primary carbohydrate metabolism during grape berry development and discussed the relationship between these metabolite changes and transcriptional and translational modifications within the fruit. Similarly, Wang et al. (2017) reported close correlations between the 
metabolome and the proteome at the interface of primary and secondary metabolism in developing $V$. vinifera Early Campbell fruits. Down-regulation of carbohydrate production and protein synthesis is a conserved response of plants to abiotic stresses (Cramer et al. 2011). This may be a way for plants to save energy, and reflects a shift from plant growth to mechanisms of protection. However, with the exception of organic acids, the effects of high temperature on berry primary metabolism in general are still poorly described (Serrano et al. 2017). It is well known that warm climatic conditions enhance the degradation of malate in grapevine fruits, leading to a decrease in total acidity (Sweetman et al. 2014). Sugar metabolism is desynchronized from organic acid metabolism in ripening berries at high temperatures (Rienth et al. 2016). The micro-environment plays an active role in controlling the dynamics of primary metabolite accumulation that affect fruit composition. For instance, heating strongly alters the berry concentration of various amino acids, including phenylalanine and $\gamma$ aminobutyric acid, and decreases malate content (Lecourieux et al. 2017). Integrating microclimatic parameters and metabolomic analysis, Reshef et al. (2017) reported that solar irradiance affected the overall levels and patterns of accumulation of sugars, organic acids, amino acids and phenylpropanoids, across the grape cluster. The relationship between the diurnal microclimatic changes (radiation and temperature) and the berry metabolic dynamics was recently described (Reshef et al. 2019). The present study provides additional evidence about the harmful effects of heat on berry primary metabolism through the quantification of 31 metabolite intermediates related to sugar accumulation, glycolysis, and the TCA cycle, as well as through the identification of numerous proteins related to the corresponding metabolic pathways whose abundance is affected by HS. Among the 31 metabolites quantified, 14 were significantly impacted upon HT, with reduced contents in warmed berries for all of these (Figure 3, Supplementary Table S10). Some intermediates were more affected when the HT was applied during the green stage (glycerate, fumarate), and others during ripening (T6P and S6P), whereas the remaining ones were negatively impacted at all three developmental stages (pyruvate, shikimate, G3P, 3-PGA, G6P, Man6P, F6P). Reduced malate contents were also observed under HS, including the green stage (Figure 3). These primary metabolite profiles coincide with a dramatic down-regulation of numerous enzymes related to carbohydrate and energy metabolism in heat-treated berries (48 out of 56 DAPs, Supplementary Table S9), and more than $70 \%$ of these DAPs were repressed during the ripening period. Using a Cabernet Sauvignon cell suspension culture subjected to HS $\left(42^{\circ} \mathrm{C}\right)$, George et al. (2015) observed a similar decline in proteins related to sugar metabolism. Our results highlighted changes in many metabolic pathways in grape berries exposed to heat, possibly due to the inhibitory effect of elevated temperature on metabolic enzyme activities from these pathways.

Several enzymes from the pathways of sugar and sugar-phosphate metabolism were less abundant in heated berries, including a fructokinase (FRK, VIT_14s0006g01410) and two hexokinases (HXK, VIT_18s0001g14230, VIT_11s0016g03070). The decrease in these enzymes may contribute to the lower concentration in sugar phosphates (T6P, S6P, G6P and F6P) under heat, since the hexoses 
(glucose and fructose) resulting from cleavage of imported sucrose can be converted to hexose phosphates by FRK and HXK in the cytosol (Stein and Granot 2018). In plants, trehalose 6-phosphate (T6P) acts as a signal of sucrose availability connecting plant growth and development to its metabolic status, and it was reported that T6P levels can exhibit dynamic responses to environmental cues (Figueroa and Lunn 2016). An increase in T6P content was observed in berries from veraison on, but this increase was lower under heat (Figure 3, Supplementary Table S10). In some plants, T6P inhibits the SnRK1 Ser/Thr protein kinase, in turn contributing to a reduction in anthocyanin content (Baena-Gonzalez et al. 2007). It is thus tempting to speculate that the increase in T6P concentration from veraison onwards contributes to anthocyanin accumulation through repression of SnRK1, and that this regulatory process is less effective under heat. However, the roles of T6P as a signalling molecule and the SnRK1/T6P pathway during the berry ripening process and in HT response remain to be demonstrated. In sink organs such as developing berries, sucrose cleavage is carried out either by invertase (INV) to yield glucose and fructose, or by sucrose synthase (SUS) to yield UDPG and fructose. Our proteomic analysis revealed a strong accumulation of a SUS isoform after HT at veraison (SUS2, VIT_05s0077g01930). However, glucose, fructose and sucrose contents were not differentially altered by heat treatment (Figure 3, Supplementary Table S10), whereas a delay in the increase in total soluble solids (TSS) content was observed in developing berries after heat exposure during the green stage (Lecourieux et al. 2017). Accumulation of SUS may be a sign of hypoxia resulting from increased respiration rate under high temperature conditions, thus consuming oxygen faster than it can diffuse into the bulky grape berry tissue. Such as AtSUS1 and AtSUS4 in Arabidopsis, SUS genes are described as hypoxic responsive genes and a role for sucrose synthase as part of the acclimation mechanism to anoxia in dicots was proposed (Santaniello et al., 2014).

The present study also revealed the lower abundance of many glycolytic enzymes (9 DAPs) in warmed berries, mostly during ripening, together with the reduced content of some glycolytic intermediates (Fru6P, 3-PGA, pyruvate). A similar decrease in abundance of glycolytic enzymes or glycolytic intermediates was also reported for some grape varieties including Cabernet Sauvignon, when berries ripen under normal growth conditions (Giribaldi et al. 2007; Dai et al. 2013; MartinezEsteso et al. 2013). Thus, the consequence of heat stress on the glycolytic pathway remains unclear since the glycolytic flux might have been maintained of even increased at high temperature although the decrease of some glycolytic-related DAPs. Disturbing the glycolytic pathway may impair the generation of energy (ATP), reducing equivalents (NADH) and various intermediates required for the production of amino acid, lipids and secondary metabolites. For example, it has been reported that cell energy, reducing power and $\alpha$-ketoglutarate availability are potential drivers for flavonoid biosynthesis in grape cells (Soubeyrand et al. 2018).

The TCA cycle is a central metabolic hub since it generates energy, reducing power and carbon 416 skeletons. Several enzymes from the TCA cycle were repressed in heated berries but consequences on 417 the corresponding TCA intermediates were not obvious within the time frame of the analysis. The 
transcript levels of $\mathrm{MDH}$, which catalyzes a reversible reaction between oxaloacetate and malate, and ME which oxidizes malate to pyruvate, were reported to increase during grape berry ripening. This higher expression might contribute to the decline of malate concentration after veraison (MartinezEsteso et al., 2011; Wang et al, 2017). In our study, however, heat exposure reduced protein amount of both enzymes in ripening fruits (MDH: VIT_10s0003g01000, VIT_19s0014g01640, VIT_00s0373g00040; ME: VIT_15s0046g03670, VIT_11s0016g03210), therefore questioning their precise role in hastening the malate decrease under heat. The amount of a phosphoenolpyruvate carboxylase (PEPC, VIT_19s0014g01390) was also reduced by HT at the green stage. This may contribute to lower the amount of malate under heat before veraison (Figure 3), since the first step of anaplerotic malate synthesis involves the carboxylation of PEP by PEPC (Sweetman et al. 2009). However, the loss of malate during ripening has been attributed to increased degradation rather than decreased synthesis pre-veraison (Ruffner et al. 1976; Sweetman et al. 2014). Accordingly, PEPC activity decreases in pre-veraison berries with day heating, and malate content did not correlate with changes in PEPC activity (Sweetman et al. 2014). The PEPC activity is highly regulated by reversible protein phosphorylation and mono-ubiquitination, which affects its sensitivity to feedback inhibition by malate (Ruiz-Ballesta et al. 2016). Thus, changes in the phosphorylation and/or the ubiquitination status of PEPC might be more important than changes in total PEPC protein abundance. Energyconsuming processes such as gluconeogenesis may also be impacted in ripening berries exposed to HT, with three down-regulated enzymes (MDH, PEPCK and isocitrate lyase). Lower MDH amounts would reduce the accumulation of oxaloacetate (OAA), required for PEP formation through phosphoenolpyruvate carboxykinase activity (PEPCK). In normal growth conditions, both PEPCK activity and transcript abundance are increased in berries after veraison (Walker et al. 2015). In ripening grapes, PEPCK may function in gluconeogenesis when malate released from the vacuole exceeds the demand from other malate-consuming processes (Walker et al. 2015).

\section{Heat stress promotes changes in lipid metabolism and cell wall remodelling}

444 The functional category "Lipid metabolism" was particularly affected in heat-exposed berries since all 445 the lipid-related proteins (20 DAPs) identified in our work were negatively regulated after HT

446 (Supplementary Table S2). Moreover, we also observed that warmed berries contain lower amount 447 of glycerol 3-phosphate, precursor of the membrane glycerolipids (Figure 3). These lipid-related 448 DAPs are involved in fatty acid (FA) synthesis, FA elongation or FA degradation, among which were the following enzymes: acetyl-CoA carboxylase (ACC, VIT_18s0001g04980, VIT_11s0065g00360), glycerol-3-phosphate acyltransferase (GPAT, VIT_15s0046g02400), beta-ketoacyl-CoA synthase (KCS, VIT_13s0067g03890) and phosphoinositide phosphatase (SAC, VIT_04s0044g00030). ACC

452 proteins catalyse the carboxylation of acetyl-CoA to form malonyl-CoA during fatty acid synthesis 453 (Sasaki and Nagano 2004). The cytosolic ACCase contributes to the synthesis of very-long chain fatty 454 acids, with a role in membrane stability and biosynthesis of flavonoids. Its lower abundance in 
warmed berries may negatively impact the flavonoid accumulation upon veraison. The heat-repressive effects observed at the protein level may also lead to a deep remodelling of the berry protection system. Particularly, the down-regulation of some proteins such as GPAT and KCS may disturb the berry protective barrier, namely the cuticle, since these two proteins belong to families involved in cutin and wax biosynthesis, respectively (Guo et al. 2016; Petit et al. 2016). The strongest translational repression was observed for a protein from the SAC (suppressor of actin) family ( $\log _{2} \mathrm{FC}:-6.22$ ) when the HS was applied during the green stage. SAC proteins are phosphatases that hydrolyze polyphosphoinositides, and roles in stress responses, cell wall formation, vacuolar trafficking and vacuolar morphology and function have been demonstrated in plants (Novakova et al. 2014). Among the known effects of high temperatures, one of the most relevant is the alteration of membrane-linked processes due to modifications in membrane fluidity and permeability (Niu and Xiang 2018). Heat stress decreases the total content of lipids and glycolipids (Escandon et al. 2018). To preserve membrane integrity under elevated temperatures, plants can regulate the ratio of bilayer to non-bilayerforming lipids (Welti et al. 2007). Plant thermotolerance might also be improved by reducing the membrane content of unsaturated fatty acids or by accumulating more saturated fatty acids prior to HS, thus helping to maintain optimal membrane fluidity (Higashi et al. 2015; Escandon et al. 2018). Accordingly, we found that two desaturase proteins (VIT_05s0094g00750, VIT_00s0499g00030) were down-regulated in warmed berries. Membrane components may also be involved in initiating key signalling pathways that lead to the appropriate plant responses to heat (Niu and Xiang 2018). Consequences of the heat-induced lipid metabolism changes for berry development and quality remain to be determined.

The cell wall forms a dynamic boundary for plant cells and plays important roles during grape berry development, governing the potential for cell expansion during fruit growth and modulating the texture of mature berries through the depolymerisation and the solubilisation of cell wall polymers (Goulao et al. 2012b). Cell wall remodelling also constitutes an important component of plant responses to HS that maintain overall function and growth, although the cell wall factors contributing to the acquisition of plant thermotolerance remain largely unknown (Wu et al. 2018). Our previous transcriptomic analysis highlighted the strong effect of HT on genes involved in cell wall homeostasis, and especially on enzymes contributing to cell wall expansion and loosening such as xyloglucan endotransglycosylase and expansins (Lecourieux et al. 2017). At the protein level, most of the 25 DAPs related to the category "cell wall" displayed lower amounts in heated berries, except for a few proteins among which were two pectin methylesterases (PME, VIT_07s0005g00730, VIT_11s0016g00290) and two polygalacturonases (PG, VIT_02s0025g01330, VIT_08s0007g08330) that accumulate in ripening berries exposed to heat. Both PME and PG are implicated in pectin disassembly and fruit softening process, but it is difficult to assess the impact of changes in these four proteins, since both enzymes belong to large families, with 36 PMEs and 60 PGs being annotated in the reference grape genome (Goulao et al. 2012a). However, there is increasing evidence that cell wall-modifying 
enzymes are involved in plant responses to HS, and PMEs appear to be key players in the process $(\mathrm{Wu}$ et al. 2018). Similar observations were made in fruits of other species exposed to high temperature, such as strawberry (Langer et al. 2018).

\section{Identification of proteins with a potential role in berry responses to heat}

Global warming represents a substantial risk for the sustainability of wine production in many regions. Plant breeding combined with molecular plant biotechnology has the potential to deliver stable yields and quality under warmer climate conditions, but this requires the identification of key traits of tolerance to heat (Torregrosa et al. 2017). Our proteomic study revealed 54 DAPs related to the functional category "Stress" and mainly belonging to the "abiotic/heat stress" cluster (Supplementary Table S7; 35 out of the 54 "stress" DAPs). Most of the proteins associated with the "heat stress" category were over-accumulated, mainly at veraison stage, and all were members of the heat shock protein (HSP) family. Looking for potential protective mechanisms activated in berries exposed to HT, we paid particular attention to up-regulated proteins previously described in the HS responses and thermotolerance in other plant species (Table 2; Supplementary Tables S7 and S12). We also listed some proteins that increased in abundance under HT and thus have a putative role in stress tolerance. These proteins (Table 2) are potential markers for developing or selecting grape varieties that are better adapted to warmer climate or the extreme heat waves that are expected due to climate change.

Cabernet Sauvignon berry can improve its HS response abilities by elevating the levels of particular proteins associated with the maintenance of protein homeostasis (synthesis, folding and degradation). HSP/chaperones are considered as powerful buffers against environmental stress including HS. Their chaperone functions include not only protein folding, but also signalling and protein targeting and degradation (Bokszczanin and Fragkostefanakis 2013). Data collected over the last decades suggest that members of the $\mathrm{HSP} /$ chaperone network are valuable targets for engineering multiple stress resistance in crops (Jacob et al. 2017). Among the 30 up-regulated HSPs in heatexposed berries, four of these were increased irrespective of the fruit developmental stage (HSP70, HSP90, HSP101, HSP17.6II), and all of these were described as required for thermotolerance in various plant species (Table 2). Another up-regulated protein under HS corresponds to a Bcl-2associated athanogene isoform (BAG). Plant BAGs are multifunctional proteins that regulate cell development and contribute to cytoprotection from pathogen attack and abiotic stress (Doukhanina et al. 2006). In particular, AtBAG7 was described to be a key player of the heat-induced unfolded protein response (UPR) pathway that alleviates the detrimental effects of accumulation of misfolded proteins

524 (Li et al. 2017). VvROF1 abundance was also increased in HS conditions. In Arabidopsis, AtROF1

525 encodes a peptidyl prolyl isomerase catalysing the cis/trans isomerization of peptide bonds N-terminal

526 to proline residues within polypeptide chains. AtROF1 is transcriptionally induced by HT and is 527 involved in acquired thermotolerance through the interaction with HSP90.1 and HSFA2 (Meiri and 
Breiman 2009). We also observed that two thaumatin-like proteins (VvTLPs) from the osmotin subfamily strongly accumulated in heat stressed berries. The grape genome contains 33 VvTLPs (Yan et al. 2017), and this family is known to be involved in biotic and abiotic stress responses including grapevine (Liu et al. 2010). Osmotins have been shown to have multiple functions in enhancing stress tolerance in many plant species, although the mechanisms by which osmotins mediate plant response to abiotic stress are not well established (de Jesus-Pires et al. 2019). Finally, a strong increase in the translation initiation factor VveIF5 was detected in heated berries (Table 2). The role of eIF5 in thermotolerance was described in Arabidopsis and pea (Suragani et al., 2011; Zhang et al., 2017).

How plants sense and transduce the HT signal is still an important topic to be addressed. It was reported that phytochromes function as plant thermosensors (Jung et al. 2016). Transduction of the HT signal involves various players ( $\mathrm{Li}$ et al. 2018), including members of the plasma membrane cyclic nucleotide gated calcium channel family (CNGC). In Arabidopsis, CNGC2 and CNGC6 were described as heat sensors, contributing to the $\mathrm{Ca}^{2+}$ signalling induced by HT and leading to the onset of plant acquired thermotolerance (Finka et al. 2012). Whereas CNGC6 gene is ubiquitously expressed in Arabidopsis (Gao et al. 2012), our results revealed that the protein abundance of the grape ortholog VvCNGC2 increased after berry exposure to heat, underlining the need for de novo synthesis of this protein to achieve its role in thermotolerance.

Integration of elevated temperature, signal transduction and the appropriate stress response is mediated, at least partially, by plant hormones ( $\mathrm{Ku}$ et al. 2018). Several proteins related to hormone homeostasis were seen to be more abundant in heat-exposed berries (Table 2). Four abscisic acid (ABA)-related DAPs were up-regulated in the present study. The first DAP is a 9-cis-epoxycarotenoid dioxygenase (NCED). This enzyme catalyses the first committed step in ABA biosynthesis (Tan et al. 1997) and NCED overexpression improves drought tolerance in grape (He et al. 2018). At the transcript level, a mixed picture has emerged for the NCED isogenes in HS grape berries (CarbonellBejerano et al. 2013; Rienth et al. 2014a; Lecourieux et al. 2017). The second ABA-related DAP was GER5/GRE5, a protein closely related to GEM (GLABRA2 Expression Modulator) and belonging to a subfamily of the GRAM domain-containing proteins (Mauri et al. 2016). In heat-stressed berries, GER5 was up-regulated at both mRNA and protein levels (Supplementary Table S11). GER5 and closely related GRAM domain genes (GER1, GEM) were proposed to be required in the reproductive development of Arabidopsis whereas a putative role in abiotic stress responses remains unclear (Bhatta et al. 2018). The third ABA-related DAP is an ABA-, stress-, and ripening- (ASR) induced protein known to play prominent roles in the protection of plants against abiotic stress (Gonzalez and Iusem 2014). For instance, the grape ASR VvMSA was reported to be involved in responses to water deficit (Medici et al. 2014). The last ABA-related DAP is RACK1 (receptor for activated C kinase 1).

562 In rice, this protein positively regulates seed germination by controlling endogenous levels of ABA 563 and $\mathrm{H}_{2} \mathrm{O}_{2}$ (Zhang et al. 2014). More broadly, plant RACK1 proteins regulate various signalling 564 pathways ranging from developmental processes such as seed germination, flowering and leaf 
initiation, to immune and stress responses against pathogens and environmental stimuli (Islas-Flores et al. 2015). Another phytohormone-related DAP was a brassinosteroid-related protein phosphatase which accumulated in heated berries. In Arabidopsis, this protein is one of a four-member gene family (BSL, for BRI1-SUPPRESSOR1 Like) shown to participate in brassinosteroid signalling (Maselli et al. 2014), and potentially involved in stress tolerance (Gruszka 2018).

Heat stress is accompanied by oxidative stress, which may trigger adverse effects through oxidative damage of cell membranes and important macromolecules (Bokszczanin and Fragkostefanakis 2013). Therefore, redox regulation and signalling have been recognised as crucial mechanisms for acute responses to HT (Katano et al. 2018). Our proteomic analysis of HT berries highlighted several upregulated DAPs with antioxidant properties, including two glutathione S-transferases (GSTs), a glutathione reductase (GR, VIT_07s0141g0039), one catalase, a protein-disulfide isomerase (PDI), an aldo-keto reductase (AKR), two mannitol dehydrogenases (MTD) and an $S$-nitrosoglutathione reductase (GSNOR). Glutathione S-transferases belong to a well-characterized detoxification enzyme family, catalyzing the conjugation of the reduced glutathione tripeptide (GSH) to electrophilic substrates (Kumar and Trivedi 2018). GSTs quench reactive molecules through the addition of GSH and protect the cell from oxidative damage. Accordingly, plant GSTs play an important role in abiotic and biotic stress responses (Nianiou-Obeidat et al. 2017). The two up-regulated GSTs were observed at veraison but an opposite pattern was seen at ripening with five GST isoforms being strongly repressed at the protein level. This GST down-regulation observed under HT may negatively impact the accumulation efficiency of flavonoids into the vacuolar compartment of ripening berries. Indeed, GSTs function as non-enzymatic carriers in intracellular transport, allowing the accumulation of flavonoid-GSH conjugates into vacuoles (Petrussa et al. 2013). The GST-mediated transport of anthocyanins and proanthocyanidins has been established in grape as well (Perez-Diaz et al. 2016). Among the four other heat-affected proteins, GR catalyses the reduction of glutathione disulfide (GSSG) to GSH, and its role in heat tolerance was described in different plant species (Jegadeesan et al. 2018). The ROS detoxifying enzyme catalase is considered as an acclimation protein required for basal thermotolerance (Vanderauwera et al. 2011), whereas PDI encodes an oxidoreductase enzyme belonging to the thioredoxin superfamily. PDI can be considered as a folding enzyme since it catalyses the formation of correct disulfide bridges between the cysteine residues in proteins to maintain ERhomeostasis (Park and Seo 2015). In potato, StPDI1 was found to interact with a sucrose transporter (StSUT1) (Krugel et al. 2012), and a role in abiotic stress tolerance and $\mathrm{H}_{2} \mathrm{O}_{2}$ detoxification was suggested (Eggert et al. 2016). Recently, the heterologous over-expression of a Methanothermobacter thermautotrophicus PDI with a chaperone function and disulfide isomerase activity could confer thermotolerance to transgenic rice (Wang et al. 2018). The aldo-keto reductase (AKR) superfamily contains proteins able to reduce a broad spectrum of substrates, ranging from simple sugars to

600 potentially toxic aldehydes. Plant AKRs are involved in diverse metabolic reactions including reactive 601 aldehyde detoxification, biosynthesis of osmolytes, secondary metabolism and membrane transport. 
These proteins may also confer multiple stress tolerance (Sengupta et al. 2015), including heat stress tolerance as reported in rice (Turoczy et al. 2011). Two mannitol dehydrogenases (MTD) increased in

604 abundance in grape berries exposed to HT. The role of mannitol and by extension, its catabolic enzyme MTD, is well established in resistance to both biotic and abiotic stresses. Several studies suggest that mannitol protects plants from various abiotic stresses by acting as an osmoprotectant and by quenching the damaging ROS (Patel and Williamson 2016). In grapevine, VvMTD1 was described as involved in water-deficit stress tolerance (Conde et al. 2015). Finally, GSNOR has an important function in the homeostasis of NO (nitric oxide), which is considered as a broad-spectrum anti-stress molecule when acting at low concentration in plants. Whereas NO was described to accumulate in

611 tobacco exposed to HT (Gould et al. 2003), the key role of GSNOR1-mediated de-nitrosylation in

612 thermotolerance was revealed by the characterization of Arabidopsis hot5 (sensitive to hot 613 temperatures) knock-out mutants (Lee et al. 2008). Taken together, these up-regulated and redox614 related proteins may play a role in signalling as well as in preventing harmful effects of ROS and reactive nitrogen species in berries under HS conditions.

Finally, our proteomic work highlighted the heat-induced accumulation of two proteins related to vitamin metabolism, namely VvPDX1.2 and VvPANK (Table 2). The pseudoenzyme PDX1.2 (Pyridoxine biosynthesis 1) is a noncatalytic homolog of the PDX1 subunit of the vitamin $\mathrm{B}_{6}$

619 biosynthesis protein machinery. Transcriptionally regulated by HsfA1, PDX1.2 serves to stabilize the 620 catalytic PDX1s under HT, thereby maintaining vitamin $\mathrm{B}_{6}$ homeostasis in plants (Dell'Aglio et al. 621 2017). AtPDX1.2 was reported as essential for plant growth under heat and oxidative stress conditions 622 (Moccand et al. 2014). The second up-regulated protein corresponds to a pantothenate kinase (PANK).

623 Pantothenate (known as vitamin B5) is the key precursor of CoA and acyl carrier protein, which are essential co-factors for many metabolic enzymes (Raman and Rathinasabapathi 2004). The PANK converts pantothenate to phosphopantothenate, using ATP as phosphate donor. PANK activity plays a critical role in regulating intracellular coenzyme A $(\mathrm{CoA})$ levels in bacteria and animals but little is known about the role of this enzyme in plants (Ottenhof et al. 2004). It was suggested that an increased level of CoA, through an increased PANK activity, may be responsible for improved plant growth and stress resistance (Rubio et al. 2008).

\section{Conclusion}

Global warming represents a substantial risk for the sustainability of wine production in many regions. Plant breeding combined with molecular plant biotechnology have the potential to deliver stable yields and quality under warmer climate conditions, but this requires the identification of key traits of tolerance to heat. To this end, we combined omics approaches to decipher the molecular components and processes affected in developing Cabernet Sauvignon berries exposed to heat. In the present study, 
substantial role in heat tolerance. Our data also show that there is not a straightforward correlation between the heat-modulated berry transcriptome and proteome, indicating the major involvement of post-transcriptional regulation under heat stress. These pronounced changes contribute on the one hand to generate fruit damaging effects, including disruption of carbohydrate and secondary metabolism, and on the other hand to mobilize key heat-signalling players as well as protective molecules such as antioxidants and chaperones (Figure 5). In summary, these findings help elucidate heat-triggering effects on developing grape berries and identify genes and proteins that potentially control heat acclimation in grapevine. The functional characterization of some putative candidates is in progress.

\section{MATERIAL AND METHODS}

\section{Plant material, temperature and sampling}

650 Elevated temperature $\left(+8^{\circ} \mathrm{C}\right)$ was directed on clusters of $V$. vinifera Cabernet Sauvignon fruiting cuttings. The HT was applied at three different berry developmental stages and maintained throughout the light period (7:00 am to 7:00 pm) until harvesting. To separate short- and long-term responses, berries were collected after 1 and 7 days of treatment. Details of the experimental protocol and sampling were provided in Lecourieux et al. (2017). The same pools of deseeded berries were used for both the transcriptomic analysis reported in Lecourieux et al. (2017) and the proteomic analysis reported here.

\section{Tissue preparation and total protein extraction}

659 Each biological replicate contained 25 pooled berries underwent independent protein extraction using 660 a protocol adapted from Lücker et al. (2009) and Martinez-Estezo et al. (2011). Briefly, deseeded 661 berries were ground to a fine powder in a mortar with liquid nitrogen and $3 \mathrm{~g}$ of frozen ground tissue 662 were used to prepare a total protein extract. Pectins and pigments were removed after incubation of the 663 frozen tissues in $25 \mathrm{~mL}$ of a cold $\left(-20^{\circ} \mathrm{C}\right)$ ethyl acetate: ethanol $\left(1: 2(\mathrm{v} / \mathrm{v})\right.$ for $30 \mathrm{~min}$ at $-20^{\circ} \mathrm{C}$ with 664 repeated vortexing. The protein extract was precipitated by centrifugation for $3 \mathrm{~min}$ at $21000 \times g$ at $6654{ }^{\circ} \mathrm{C}$, and a second ethyl acetate: ethanol wash was performed in a similar way. The pellet was next 666 extracted twice with cold $\left(-20^{\circ} \mathrm{C}\right) 100 \%$ acetone by vortexing and centrifuging, as before. The pellet 667 was transferred to a mortar and dried in a fume hood until complete acetone evaporation. The dried pellet was finely ground after addition of $1 / 3 \mathrm{vol}$ of sand, and washed with $1.5 \mathrm{~mL}$ chilled $10 \%(\mathrm{w} / \mathrm{v})$ trichloroacetic acid (TCA) in acetone. This washing step was repeated seven times. This was followed

670 by two washes with aqueous $10 \%(\mathrm{v} / \mathrm{v})$ TCA, two with chilled $80 \%(\mathrm{v} / \mathrm{v})$ acetone, and drying at $4{ }^{\circ} \mathrm{C}$. 671 Each washing step included incubation at $-20^{\circ} \mathrm{C}$ for $20 \mathrm{~min}$ followed by centrifugation for $3 \mathrm{~min}$ at $67221000 \times g$ at $4{ }^{\circ} \mathrm{C}$. Subsequently the dried pellet was resuspended in $500 \mu \mathrm{L}$ protein extraction buffer 673 containing: $0.7 \mathrm{M}$ sucrose, $0.1 \mathrm{M} \mathrm{KCl}, 0.5 \mathrm{M}$ Tris- $\mathrm{HCl}(\mathrm{pH} 7.5), 50 \mathrm{mM}$ EDTA, 1\% PVPP, $1 \%$ 
674 DTT and protease inhibitor cocktail (Roche, Germany), and incubated at room temperature (RT) for

67530 min with intermittent vortexing. Then, an equal volume of Tris-saturated phenol ( $\mathrm{pH} 7.5)$ was

676 added, the sample was incubated at RT for $30 \mathrm{~min}$ with vortexing every $5 \mathrm{~min}$. After centrifugation at $67715,000 \times g$ at RT for $40 \mathrm{~min}$, the phenol phase in the upper layer was transferred into a new 2-mL

678 Eppendorf tubes and the remaining aqueous lower phase was re-extracted with another $500 \mu \mathrm{L}$ Trissaturated phenol ( $\mathrm{pH}$ 7.5). The two phenol phases were combined and washed twice with an equal volume of phenol washing buffer $(0.7 \mathrm{M}$ sucrose, $0.1 \mathrm{M} \mathrm{KCl}, 0.5 \mathrm{M}$ Tris (pH 7.0, $50 \mathrm{mM}$ EDTA, $1 \%$ DTT, and protease inhibitor cocktail). Proteins contained in the organic phase were precipitated overnight at $4{ }^{\circ} \mathrm{C}$ with 5 volumes of $0.1 \mathrm{M}$ ammonium acetate in methanol. Precipitated proteins were washed three times in $0.1 \mathrm{M}$ ammonium acetate in methanol and twice in ice-cold $80 \%$ (v/v) acetone. All these precipitating and washing steps included incubation for $30 \mathrm{~min}$ followed by centrifugation at $15,000 \times g$ at $4^{\circ} \mathrm{C}$ for $40 \mathrm{~min}$. Finally, proteins were dissolved in $200 \mu \mathrm{L}$ freshly prepared solubilization solution (7 M urea, $70 \mathrm{mM} \mathrm{SDS}, 20 \mathrm{mM} \mathrm{DTT}$ ) and quantified according to the Bradford method (Bradford, 1976) with bovine serum albumin as standard.

\section{Sample preparation and protein digestion}

Thirty $\mu \mathrm{g}$ of each protein sample (three biological replicates for each condition; 12 conditions in total: three stages $\mathrm{x}$ two treatments $\mathrm{x}$ two treatment durations) were solubilized in Laemmli buffer and were separated by SDS-PAGE in a 10\% (w/v) acrylamide gel. After colloidal blue staining, each lane was horizontally divided into four parts of equal length and each part was subsequently cut in $1 \mathrm{~mm} \times 1$ $\mathrm{mm}$ gel pieces. Gel pieces were destained in $25 \mathrm{mM}$ ammonium bicarbonate dissolved in $50 \%(\mathrm{v} / \mathrm{v})$ acetonitrile $(\mathrm{ACN})$, rinsed twice in ultrapure water and dehydrated in $100 \% \mathrm{ACN}$ for $10 \mathrm{~min}$. After ACN removal, gel pieces were dried at room temperature, covered with proteolysis solution (containing $10 \mathrm{ng} / \mu 1$ trypsin dissolved in $40 \mathrm{mM} \mathrm{NH}_{4} \mathrm{HCO}_{3}$ and $10 \%(\mathrm{v} / \mathrm{v}) \mathrm{ACN}$ ), rehydrated at $4{ }^{\circ} \mathrm{C}$ for $10 \mathrm{~min}$, and finally incubated overnight at $37^{\circ} \mathrm{C}$. The gel pieces were then incubated for $15 \mathrm{~min}$ in $40 \mathrm{mM} \mathrm{NH}_{4} \mathrm{HCO}_{3}$ and $10 \%(\mathrm{v} / \mathrm{v}) \mathrm{ACN}$ at room temperature with rotary shaking. The supernatant was collected, and an $\mathrm{H}_{2} \mathrm{O} / \mathrm{ACN} /$ formic acid (47.5:47.5:5 by volume) extraction solution was added and gel slices incubated for $15 \mathrm{~min}$. The extraction step was repeated twice. Supernatants were pooled and concentrated in a vacuum centrifuge to a final volume of $40 \mu \mathrm{L}$. Digests were finally acidified by addition of $2.4 \mu \mathrm{L}$ of $5 \%(\mathrm{v} / \mathrm{v})$ formic acid and the resulting peptide mixtures stored at $-20{ }^{\circ} \mathrm{C}$ until analysis.

\section{nLC-MS/MS analysis}

707 Peptide mixtures were analyzed on an Ultimate 3000 nanoLC system (Dionex, Amsterdam, The

708 Netherlands) coupled to a nanospray LTQ-Orbitrap XL mass spectrometer (ThermoFinnigan, San

709 Jose, USA). Ten microliters of peptide mixtures were loaded onto a 300- $\mu \mathrm{m}$-inner diameter x 5-mm $710 \mathrm{C}_{18}$ PepMap $^{\mathrm{TM}}$ trap column (LC Packings) at a flow rate of $30 \mu \mathrm{L} / \mathrm{min}$. The peptides were eluted from 
711 the trap column onto an analytical 75-mm id x 15-cm C18 Pep-Map column (LC Packings) with a 5-

$71240 \%$ linear gradient of solvent B in 105 min (solvent A was $0.1 \%$ formic acid in $5 \% \mathrm{ACN}$, and solvent

713 B was $0.1 \%$ formic acid in $80 \% \mathrm{ACN}$ ). The separation flow rate was set at $200 \mathrm{~nL} / \mathrm{min}$. The mass

714 spectrometer operated in positive ion mode at a $1.8-\mathrm{kV}$ needle voltage and a $39-\mathrm{V}$ capillary voltage.

715 Data were acquired in a data-dependent mode alternating a Fourier transform mass spectrometry

716 (FTMS) scan survey over the range $\mathrm{m} / \mathrm{z}$ 300-1700 and six ion trap MS/MS scans with CID (Collision

717 Induced Dissociation) as activation mode. MS/MS spectra were acquired using a $3-\mathrm{m} / \mathrm{z}$ unit ion

718 isolation window and a normalized collision energy of $35 \%$. Only +2 and +3 charge-state ions were

719 selected for fragmentation. Dynamic exclusion duration was set to 30s.

\section{Database search and MS data processing}

722 Data were searched using the SEQUEST algorithm (supported by the Proteome Discoverer 1.4 723 software; Thermo Fisher Scientific Inc.) against a subset of the 2012.01 version of UniProt database 724 restricted to Vitis vinifera Reference Proteome Set (29,817 entries). Spectra from peptides higher than $5000 \mathrm{Da}$ or lower than $350 \mathrm{Da}$ were rejected. The search parameters were as follows: mass accuracy of the monoisotopic peptide precursor and peptide fragments was set to $10 \mathrm{ppm}$ and 0.8 Da respectively. Only $b$ - and $g$-ions were considered for mass calculation. Oxidation of methionines (+16 Da) was considered as a variable modification. Two missed trypsin cleavages were allowed. Peptide validation was performed using the Percolator algorithm (Käll et al. 2007), and only "high confidence" peptides were retained corresponding to a $1 \%$ false positive rate at the peptide level.

\section{Label-Free Quantitative Data Analysis}

733 Raw LC-MS/MS data were imported into the Progenesis LC-MS 4.0 (Non Linear Dynamics) 734 software. Data processing includes the following steps: (i) Features detection, (ii) Features alignment 735 across the six samples for each part, (iii) Volume integration for 2-6 charge-state ions, (iv) 736 Normalization on total protein abundance, (v) Import of sequence information, (vi) ANOVA test at the 737 peptide level and filtering for features $p<0.05$, (vii) Calculation of protein abundance (sum of the 738 volume of corresponding peptides), (viii) ANOVA test at protein level and filtering for features $p$ $739<0.05$. Only non-conflicting features and unique peptides were considered for calculation at the 740 protein level. Quantitative data were considered for proteins quantified by a minimum of two peptides.

741 The mass spectrometry proteomics data have been deposited to the ProteomeXchange Consortium via the PRIDE (Perez-Riverol et al. 2019) partner repository with the dataset identifier PXD014693.

743 Protein abundance changes between control and heat-exposed fruits were considered to be 744 significant when a minimum fold change of $1.5\left(\log _{2} \mathrm{FC}>0.58\right.$ or $\left.<-0.58\right)$ was reached, with a 745 significance threshold of $p<0.05$. Only proteins identified in all three biological replicates were 746 considered for quantification. Significantly affected protein categories based on the MapMan 747 Ontology (Usadel et al., 2005) were identified using a Chi-square test. MapMan mappings for the 
748 Cribi 12X grapevine genome were based on closest homologs regarding to the Arabidopsis thaliana

749 genome. Protein annotations were taken from Grimplet et al. (2012).

750

751 Primary metabolism quantification

752 Deseeded berries were ground to a fine powder in liquid nitrogen and aliquots (15-20 mg) of frozen 753 powder were extracted with chloroform/methanol as described by Lunn et al. (2006). Primary 754 metabolites were measured by LC-MS/MS as described by Lunn et al. (2006), with modifications as 755 described in Figueroa et al. (2016) and Dai et al. (2013).

756

\section{ACKNOWLEDGMENTS}

758 The authors would like to thank Christelle Renaud and Ghislaine Hilbert for metabolite 759 quantifications. For the production of the fruiting cuttings and technical assistance during greenhouse 760 experiments, we express our gratitude to Jean Pierre Petit, Nicolas Hoquard and Guillaume Pacreau.

761

\section{FUNDING}

763 This research received funding from the Agence Nationale de la Recherche for the project 764 “DURAVITIS” (grant no. ANR-2010-GENM-004-01).

\section{AUTHOR CONTRIBUTIONS}

767 DL, FL and PP designed the research; DL oversaw the research; PP and DL performed the greenhouse 768 experiments; FL, JC, and DL carried out the protein extraction; CK performed the bioinformatics 769 analysis; RF, DL and JEL did the metabolic analysis; SC and MB did the metabolic analysis, FL, CK, 770 and DL analysed and interpreted the data; DL and FL drafted the manuscript; SD, JEL, LW and EG 771 critically revised the manuscript. All authors read and approved the final manuscript.

\section{CONFLICTS OF INTEREST}

774 The authors declare no conflicts of interest. 
Alem H, Rigou P, Schneider R, Ojeda H, Torregrosa L (2018) Impact of agronomic practices on grape aroma composition: a review. J Sci Food Agric 99: 975-985 Asproudi A, Petrozziello M, Cavalletto S, Guidoni S (2016) Grape aroma precursors in cv. Nebbiolo as affected by vine microclimate. Food chemistry 211: 947-956 Baena-Gonzalez E, Rolland F, Thevelein JM, Sheen J (2007) A central integrator of transcription networks in plant stress and energy signalling. Nature 448: 938-942 Baurle I (2016) Plant Heat Adaptation: priming in response to heat stress. F1000Research 5:

Beauvoit B, Belouah I, Bertin N, Cakpo CB, Colombié S, Dai Z, Gautier H, Génard M, Moing A, Roch L, Vercambre G, Gibon Y (2018) Putting primary metabolism into perspective to obtain better fruits. Annals of botany 122: 1-21 Bhatta M, Morgounov A, Belamkar V, Baenziger PS (2018) Genome-Wide Association Study Reveals Novel Genomic Regions for Grain Yield and Yield-Related Traits in Drought-Stressed Synthetic Hexaploid Wheat. Int J Mol Sci 19: Bokszczanin KL, Fragkostefanakis S (2013) Perspectives on deciphering mechanisms underlying plant heat stress response and thermotolerance. Front Plant Sci 4: 315 Carbonell-Bejerano P, Santa Maria E, Torres-Perez R, Royo C, Lijavetzky D, Bravo G, Aguirreolea J, Sanchez-Diaz M, Antolin MC, Martinez-Zapater JM (2013) Thermotolerance responses in ripening berries of Vitis vinifera L. cv Muscat Hamburg. Plant Cell Physiol 54: 1200-1216 Polyols in grape berry: transport and metabolic adjustments as a physiological strategy for water-deficit stress tolerance in grapevine. Journal of Experimental Botany 66: 889-906

Cramer GR, Urano K, Delrot S, Pezzotti M, Shinozaki K (2011) Effects of abiotic stress on plants: a systems biology perspective. BMC Plant Biol 11: 163

Cuadros-Inostroza A, Ruiz-Lara S, Gonzalez E, Eckardt A, Willmitzer L, Pena-Cortes H (2016) GC-MS metabolic profiling of Cabernet Sauvignon and Merlot cultivars during grapevine berry development and network analysis reveals a stage- and cultivardependent connectivity of primary metabolites. Metabolomics : Official journal of the Metabolomic Society 12: 39

Dai ZW, Leon C, Feil R, Lunn JE, Delrot S, Gomes E (2013) Metabolic profiling reveals coordinated switches in primary carbohydrate metabolism in grape berry (Vitis vinifera L.), a non-climacteric fleshy fruit. J Exp Bot 64: 1345-1355

de Jesus-Pires C, Ferreira-Neto JRC, Pacifico Bezerra-Neto J, Kido EA, de Oliveira Silva RL, Pandolfi V, Wanderley-Nogueira AC, Binneck E, da Costa AF, Pio-Ribeiro G, PereiraAndrade G, Sittolin IM, Freire-Filho F, Benko-Iseppon AM (2019) Plant Thaumatin-like Proteins: Function, Evolution and Biotechnological Applications. Current protein \& peptide science:

Degu A, Hochberg U, Sikron N, Venturini L, Buson G, Ghan R, Plaschkes I, Batushansky A, Chalifa-Caspi V, Mattivi F, Delledonne M, Pezzotti M, Rachmilevitch S, Cramer GR, Fait A (2014) Metabolite and transcript profiling of berry skin during fruit development elucidates differential regulation between Cabernet Sauvignon and Shiraz cultivars at branching points in the polyphenol pathway. BMC Plant Biol 14: 188

Dell'Aglio E, Boycheva S, Fitzpatrick TB (2017) The Pseudoenzyme PDX1.2 Sustains Vitamin $B<$ sub $>6</$ sub $>$ Biosynthesis as a Function of Heat Stress. Plant Physiology 174: 2098-2112 
Deloire A, Vaudour E, Carey VA, Bonnardot V, Van Leeuwen C (2005) Grapevine responses to terroir: a global approach. OENO One 39: 149-162 Doukhanina EV, Chen S, van der Zalm E, Godzik A, Reed J, Dickman MB (2006) Identification and functional characterization of the BAG protein family in Arabidopsis thaliana. Journal of Biological Chemistry 281: 18793-18801 impacts on the flavonoid composition of grapes and wine: a review of recent research. American Journal of Enology and Viticulture 57: 257-268 du Plessis K, Young PR, Eyeghe-Bickong HA, Vivier MA (2017) The Transcriptional Responses and Metabolic Consequences of Acclimation to Elevated Light Exposure in Grapevine Berries. Front Plant Sci 8: 1261 (2015) Translation initiation in plants: roles and implications beyond protein synthesis. Biologia Plantarum 59: 401-412 Eggert E, Obata T, Gerstenberger A, Gier K, Brandt T, Fernie AR, Schulze W, Kuhn C (2016) A sucrose transporter-interacting protein disulphide isomerase affects redox homeostasis and links sucrose partitioning with abiotic stress tolerance. Plant, cell \& environment 39: 1366-1380 Integrated Analysis of High-Temperature Response in Pinus radiata. Front Plant Sci 9: 485 Plaxton WC, Zeeman SC, Li Z, Schulze WX, Hoefgen R, Stitt M, Lunn JE (2016) Trehalose 6-phosphate coordinates organic and amino acid metabolism with carbon availability. The Plant journal : for cell and molecular biology 85: 410-423

Figueroa CM, Lunn JE (2016) A Tale of Two Sugars: Trehalose 6-Phosphate and Sucrose. Plant Physiology 172: 7-27

Finka A, Cuendet AF, Maathuis FJ, Saidi Y, Goloubinoff P (2012) Plasma membrane cyclic nucleotide gated calcium channels control land plant thermal sensing and acquired thermotolerance. The Plant cell 24: 3333-3348

Fraga H, Garcia de Cortazar Atauri I, Malheiro AC, Santos JA (2016) Modelling climate change impacts on viticultural yield, phenology and stress conditions in Europe. Global change biology 22: 3774-3788

Francisco RM, Regalado A, Ageorges A, Burla BJ, Bassin B, Eisenach C, Zarrouk O, Vialet S, Marlin T, Chaves MM, Martinoia E, Nagy R (2013) ABCC1, an ATP binding cassette protein from grape berry, transports anthocyanidin 3-0-Glucosides. The Plant cell 25: $860 \quad 1840-1854$

861 Gao F, Han X, Wu J, Zheng S, Shang Z, Sun D, Zhou R, Li B (2012) A heat-activated calcium-permeable channel--Arabidopsis cyclic nucleotide-gated ion channel 6--is involved in heat shock responses. The Plant journal : for cell and molecular biology 70: 1056-1069

868 Giribaldi M, Perugini I, Sauvage FX, Schubert A (2007) Analysis of protein changes cabernet sauvignon grape cells exposed to thermal stresses reveals alterations in sugar and phenylpropanoid metabolism. Proteomics: during grape berry ripening by 2 - DE and MALDI - TOF. Proteomics 7: 3154-3170 Gomez C, Conejero G, Torregrosa L, Cheynier V, Terrier N, Ageorges A (2011) In vivo grapevine anthocyanin transport involves vesicle-mediated trafficking and the contribution of anthoMATE transporters and GST. The Plant Journal 67: 960-970 
Gonzalez RM, Iusem ND (2014) Twenty years of research on Asr (ABA-stress-ripening) genes and proteins. Planta 239: 941-949 Goulao L, Fernandes J, Lopes P, Amâncio S (2012a) Tackling the cell wall of the grape berry. Bentham Science Publishers Sharjah, UAE, Goulao L, Fernandesz J, Lopes P, Amancio S (2012b) Tackling the cell wall of the grape berry. The biochemistry of the grape berry: 172

Gould K, Lamotte O, Klinguer A, Pugin A, Wendehenne D (2003) Nitric oxide production in tobacco leaf cells: a generalized stress response? Plant, cell \& environment 26: 1851-1862

Gouot JC, Smith JP, Holzapfel BP, Walker AR, Barril C (2018) Grape berry flavonoids: A review of their biochemical responses to high and extreme high temperatures. J Exp Bot:

Greer DH, Weedon MM (2012) Modelling photosynthetic responses to temperature of grapevine (Vitis vinifera cv. Semillon) leaves on vines grown in a hot climate. Plant, cell \& environment 35: 1050-1064

Greer DH, Weston C (2010) Heat stress affects flowering, berry growth, sugar accumulation and photosynthesis of Vitis vinifera cv. Semillon grapevines grown in a controlled environment. Functional Plant Biology 37: 206-214

Gruszka D (2018) Crosstalk of the Brassinosteroid Signalosome with Phytohormonal and Stress Signaling Components Maintains a Balance between the Processes of Growth and Stress Tolerance. Int J Mol Sci 19:

Guo HS, Zhang YM, Sun XQ, Li MM, Hang YY, Xue JY (2016) Evolution of the KCS gene family in plants: the history of gene duplication, sub/neofunctionalization and redundancy. Molecular genetics and genomics : MGG 291: 739-752

Havaux M (2014) Carotenoid oxidation products as stress signals in plants. The Plant Journal 79: 597-606

He R, Zhuang Y, Cai Y, Aguero CB, Liu S, Wu J, Deng S, Walker MA, Lu J, Zhang Y (2018) Overexpression of 9-cis-Epoxycarotenoid Dioxygenase Cisgene in Grapevine Increases Drought Tolerance and Results in Pleiotropic Effects. Front Plant Sci 9: 970

Higashi Y, Okazaki Y, Myouga F, Shinozaki K, Saito K (2015) Landscape of the lipidome and transcriptome under heat stress in Arabidopsis thaliana. Scientific reports 5: 10533

Islas-Flores T, Rahman A, Ullah H, Villanueva MA (2015) The Receptor for Activated C Kinase in Plant Signaling: Tale of a Promiscuous Little Molecule. Front Plant Sci 6: 1090 Jacob P, Hirt H, Bendahmane A (2017) The heat-shock protein/chaperone network and multiple stress resistance. Plant Biotechnol J 15: 405-414

James AB, Calixto CPG, Tzioutziou NA, Guo W, Zhang R, Simpson CG, Jiang W, Nimmo GA, Brown JWS, Nimmo HG (2018) How does temperature affect splicing events? Isoform switching of splicing factors regulates splicing of LATE ELONGATED HYPOCOTYL (LHY). Plant, cell \& environment 41: 1539-1550

Jegadeesan S, Chaturvedi P, Ghatak A, Pressman E, Meir S, Faigenboim A, Rutley N, Beery A, Harel A, Weckwerth W, Firon N (2018) Proteomics of Heat-Stress and EthyleneMediated Thermotolerance Mechanisms in Tomato Pollen Grains. Front Plant Sci 9: 1558

Jia KP, Baz L, Al-Babili S (2018) From carotenoids to strigolactones. J Exp Bot 69: 21892204

Jiang J, Liu X, Liu C, Liu G, Li S, Wang L (2017) Integrating Omics and Alternative Splicing Reveals Insights into Grape Response to High Temperature. Plant Physiol 173: 15021518 
Jones GV, White MA, Cooper OR, Storchmann K (2005) Climate change and global wine quality. Climatic change 73: 319-343

Jung JH, Domijan M, Klose C, Biswas S, Ezer D, Gao M, Khattak AK, Box MS, Charoensawan V, Cortijo S, Kumar M, Grant A, Locke JC, Schafer E, Jaeger KE, Wigge PA (2016) Phytochromes function as thermosensors in Arabidopsis. Science 354: 886-889 Käll L, Canterbury JD, Weston J, Noble WS, MacCoss MJ (2007) Semi-supervised learning for peptide identification from shotgun proteomics datasets. Nature methods 4: 923 Katano K, Honda K, Suzuki N (2018) Integration between ROS Regulatory Systems and Other Signals in the Regulation of Various Types of Heat Responses in Plants. Int J Mol Sci 19:

Keller M, Simm S (2018) The coupling of transcriptome and proteome adaptation during development and heat stress response of tomato pollen. BMC Genomics 19: 447 Proteomics: The Major Factors Determining Alterations in Cellular Proteome. Front Plant Sci 9: 122

Krugel U, He HX, Gier K, Reins J, Chincinska I, Grimm B, Schulze WX, Kuhn C (2012) The potato sucrose transporter StSUT1 interacts with a DRM-associated protein disulfide isomerase. Mol Plant 5: 43-62

Ku YS, Sintaha M, Cheung MY, Lam HM (2018) Plant Hormone Signaling Crosstalks between Biotic and Abiotic Stress Responses. Int J Mol Sci 19:

Kuang L, Chen S, Guo Y, Ma H (2019) Quantitative Proteome Analysis Reveals Changes in the Protein Landscape During Grape Berry Development With a Focus on Vacuolar Transport Proteins. Front Plant Sci 10: 641 Kuhn N, Guan L, Dai ZW, Wu B-H, Lauvergeat V, Gomès E, Li S-H, Godoy F, Arce-Johnson P, Delrot $S$ (2014) Berry ripening: recently heard through the grapevine. Journal of experimental botany 65: 4543-4559

Kumar S, Trivedi PK (2018) Glutathione S-Transferases: Role in Combating Abiotic Stresses Including Arsenic Detoxification in Plants. Front Plant Sci 9: 751

Langer SE, Oviedo NC, Marina M, Burgos JL, Martinez GA, Civello PM, Villarreal NM (2018) Effects of heat treatment on enzyme activity and expression of key genes controlling cell wall remodeling in strawberry fruit. Plant physiology and biochemistry : PPB / Societe francaise de physiologie vegetale 130: 334-344

Lecourieux F, Kappel C, Pieri P, Charon J, Pillet J, Hilbert G, Renaud C, Gomes E, Delrot S, Lecourieux D (2017) Dissecting the Biochemical and Transcriptomic Effects of a Locally Applied Heat Treatment on Developing Cabernet Sauvignon Grape Berries. Front Plant Sci 8: 53

Lee U, Wie C, Fernandez B0, Feelisch M, Vierling E (2008) Modulation of nitrosative stress by S-nitrosoglutathione reductase is critical for thermotolerance and plant growth in Arabidopsis. The Plant cell 20: 786-802

Li B, Gao K, Ren H, Tang W (2018) Molecular mechanisms governing plant responses to high temperatures. Journal of integrative plant biology 60: 757-779

Li Y, Williams B, Dickman M (2017) Arabidopsis B-cell lymphoma2 (Bcl-2)-associated athanogene 7 (BAG7)-mediated heat tolerance requires translocation, sumoylation and binding to WRKY29. New Phytol 214: 695-705

Ling Y, Serrano N, Gao G, Atia M, Mokhtar M, Woo YH, Bazin J, Veluchamy A, Benhamed

968 M, Crespi M, Gehring C, Reddy ASN, Mahfouz MM (2018) Thermopriming triggers splicing memory in Arabidopsis. J Exp Bot 69: 2659-2675 
Liu GT, Ma L, Duan W, Wang BC, Li JH, Xu HG, Yan XQ, Yan BF, Li SH, Wang LJ (2014) Differential proteomic analysis of grapevine leaves by iTRAQ reveals responses to heat stress and subsequent recovery. BMC Plant Biol 14: 110 Liu GT, Wang JF, Cramer G, Dai ZW, Duan W, Xu HG, Wu BH, Fan PG, Wang LJ, Li SH (2012) Transcriptomic analysis of grape (Vitis vinifera L.) leaves during and after recovery from heat stress. BMC Plant Biol 12: 174

Liu JJ, Sturrock R, Ekramoddoullah AK (2010) The superfamily of thaumatin-like proteins: its origin, evolution, and expression towards biological function. Plant Cell

\section{Rep 29: 419-436}

978 Lobell DB, Burke MB, Tebaldi C, Mastrandrea MD, Falcon WP, Naylor RL (2008) Prioritizing climate change adaptation needs for food security in 2030. Science 319: 607-610 Hajirezaei MR, Stitt M (2006) Sugar-induced increases in trehalose 6-phosphate are correlated with redox activation of ADPglucose pyrophosphorylase and higher rates of starch synthesis in Arabidopsis thaliana. The Biochemical journal 397: 139-148 Martinez-Esteso MJ, Vilella-Anton MT, Pedreno MA, Valero ML, Bru-Martinez R (2013) iTRAQ-based protein profiling provides insights into the central metabolism changes driving grape berry development and ripening. BMC Plant Biol 13: 167

Martínez-Lüscher J, Kizildeniz T, Vučetić V, Dai Z, Luedeling E, van Leeuwen C, Gomès E, Pascual I, Irigoyen JJ, Morales F (2016) Sensitivity of grapevine phenology to water availability, temperature and $\mathrm{CO} 2$ concentration. Frontiers in Environmental Science 4: 48 (2014) Revisiting the Evolutionary History and Roles of Protein Phosphatases with Kelch-Like Domains in Plants. Plant Physiology 164: 1527-1541

Mathieu S, Terrier N, Procureur J, Bigey F, Gunata Z (2005) A carotenoid cleavage dioxygenase from Vitis vinifera L.: functional characterization and expression during grape berry development in relation to C13-norisoprenoid accumulation. J Exp Bot 56: 2721-2731

999 Mauri N, Fernández-Marcos M, Costas C, Desvoyes B, Pichel A, Caro E, Gutierrez C (2016) GEM, a member of the GRAM domain family of proteins, is part of the ABA signaling pathway. Scientific reports 6: 22660

Medici A, Laloi M, Atanassova R (2014) Profiling of sugar transporter genes in grapevine coping with water deficit. FEBS letters 588: 3989-3997

Meiri D, Breiman A (2009) Arabidopsis ROF1 (FKBP62) modulates thermotolerance by interacting with HSP90.1 and affecting the accumulation of HsfA2-regulated sHSPs. The Plant journal : for cell and molecular biology 59: 387-399

Moccand C, Boycheva S, Surriabre P, Tambasco-Studart M, Raschke M, Kaufmann M, Fitzpatrick TB (2014) The pseudoenzyme PDX1. 2 boosts vitamin B6 biosynthesis under heat and oxidative stress in Arabidopsis. Journal of Biological Chemistry: jbc. M113. 540526

Nianiou-Obeidat I, Madesis P, Kissoudis C, Voulgari G, Chronopoulou E, Tsaftaris A, Labrou NE (2017) Plant glutathione transferase-mediated stress tolerance: functions and biotechnological applications. Plant Cell Rep 36: 791-805

Niu Y, Xiang Y (2018) An Overview of Biomembrane Functions in Plant Responses to High-Temperature Stress. Front Plant Sci 9: 915

Novakova P, Hirsch S, Feraru E, Tejos R, van Wijk R, Viaene T, Heilmann M, Lerche J, De Rycke R, Feraru MI, Grones P, Van Montagu M, Heilmann I, Munnik T, Friml J (2014) SAC 
phosphoinositide phosphatases at the tonoplast mediate vacuolar function in Arabidopsis. Proceedings of the National Academy of Sciences of the United States of America 111: 2818-2823

Ottenhof HH, Ashurst JL, Whitney HM, Saldanha SA, Schmitzberger F, Gweon HS, Blundell TL, Abell C, Smith AG (2004) Organisation of the pantothenate (vitamin B5) biosynthesis pathway in higher plants. The Plant Journal 37: 61-72

Park C-J, Seo Y-S (2015) Heat shock proteins: a review of the molecular chaperones for plant immunity. The plant pathology journal 31: 323

Patel TK, Williamson JD (2016) Mannitol in Plants, Fungi, and Plant-Fungal Interactions. Trends in plant science 21: 486-497

Pereira G, Gaudillere J-P, Pieri P, Hilbert G, Maucourt M, Deborde C, Moing A, Rolin D (2006) Microclimate influence on mineral and metabolic profiles of grape berries. Journal of Agricultural and Food Chemistry 54: 6765-6775

Perez-Diaz R, Madrid-Espinoza J, Salinas-Cornejo J, Gonzalez-Villanueva E, Ruiz-Lara S (2016) Differential Roles for VviGST1, VviGST3, and VviGST4 in Proanthocyanidin and Anthocyanin Transport in Vitis vinifera. Front Plant Sci 7: 1166

Perez-Riverol Y, Csordas A, Bai J, Bernal-Llinares M, Hewapathirana S, Kundu DJ, Inuganti A, Griss J, Mayer G, Eisenacher M, Perez E, Uszkoreit J, Pfeuffer J, Sachsenberg T, Yilmaz S, Tiwary S, Cox J, Audain E, Walzer M, Jarnuczak AF, Ternent T, Brazma A, Vizcaino JA (2019) The PRIDE database and related tools and resources in 2019: improving support for quantification data. Nucleic acids research 47: D442-d450

Petit J, Bres C, Mauxion JP, Tai FW, Martin LB, Fich EA, Joubes J, Rose JK, Domergue F, Rothan C (2016) The Glycerol-3-Phosphate Acyltransferase GPAT6 from Tomato Plays a Central Role in Fruit Cutin Biosynthesis. Plant Physiol 171: 894-913

Petrussa E, Braidot E, Zancani M, Peresson C, Bertolini A, Patui S, Vianello A (2013) Plant flavonoids--biosynthesis, transport and involvement in stress responses. Int J Mol Sci 14: 14950-14973

Raman SB, Rathinasabapathi B (2004) Pantothenate synthesis in plants. Plant Science 167: 961-968

Reshef N, Fait A, Agam N (2019) Grape berry position affects the diurnal dynamics of its metabolic profile. Plant, cell \& environment:

Reshef N, Walbaum N, Agam N, Fait A (2017) Sunlight Modulates Fruit Metabolic Profile and Shapes the Spatial Pattern of Compound Accumulation within the Grape Cluster. Front Plant Sci 8: 70

Rienth M, Torregrosa L, Kelly MT, Luchaire N, Pellegrino A, Grimplet J, Romieu C (2014a) Is transcriptomic regulation of berry development more important at night than during the day? PLoS One 9: e88844

Rienth M, Torregrosa L, Luchaire N, Chatbanyong R, Lecourieux D, Kelly MT, Romieu C (2014b) Day and night heat stress trigger different transcriptomic responses in green and ripening grapevine (vitis vinifera) fruit. BMC Plant Biol 14: 108

Rienth M, Torregrosa L, Sarah G, Ardisson M, Brillouet JM, Romieu C (2016) Temperature desynchronizes sugar and organic acid metabolism in ripening grapevine fruits and remodels their transcriptome. BMC Plant Biol 16: 164

Rubio S, Whitehead L, Larson TR, Graham IA, Rodriguez PL (2008) The coenzyme a biosynthetic enzyme phosphopantetheine adenylyltransferase plays a crucial role in plant growth, salt/osmotic stress resistance, and seed lipid storage. Plant Physiol 148: 546-556

Ruffner HP, Hawker JS, Hale CR (1976) Temperature and enzymic control of malate metabolism in berries of Vitis vinifera. Phytochemistry 15: 1877-1880 

New insights into the post-translational modification of multiple phosphoenolpyruvate carboxylase isoenzymes by phosphorylation and monoubiquitination during sorghum seed development and germination. J Exp Bot 67: 3523-3536

Sasaki Y, Nagano Y (2004) Plant acetyl-CoA carboxylase: structure, biosynthesis, regulation, and gene manipulation for plant breeding. Bioscience, biotechnology, and biochemistry 68: 1175-1184 Scharf KD, Berberich T, Ebersberger I, Nover L (2012) The plant heat stress transcription factor (Hsf) family: structure, function and evolution. Biochimica et biophysica acta 1819: 104-119

Schultz HR, Jones GV (2010) Climate induced historic and future changes in viticulture. Journal of Wine Research 21: 137-145 tasking soldiers involved in diverse plant metabolic processes and stress defense: A structure-function update. Journal of plant physiology 179: 40-55

1083 Serrano A, Espinoza C, Armijo G, Inostroza-Blancheteau C, Poblete E, Meyer-Regueiro C, Arce A, Parada F, Santibanez C, Arce-Johnson P (2017) Omics Approaches for Understanding Grapevine Berry Development: Regulatory Networks Associated with Endogenous Processes and Environmental Responses. Front Plant Sci 8: 1486

Shiratake K, Martinoia E (2007) Transporters in fruit vacuoles. Plant Biotechnology 24: 127-133 Peyret L, Dieuaide-Noubhani M, Merillon JM, Gibon Y, Delrot S, Gomes E (2018) Constraint-Based Modeling Highlights Cell Energy, Redox Status and alphaKetoglutarate Availability as Metabolic Drivers for Anthocyanin Accumulation in Grape Cells Under Nitrogen Limitation. Front Plant Sci 9: 421

Stein O, Granot D (2018) Plant Fructokinases: Evolutionary, Developmental, and Metabolic Aspects in Sink Tissues. Front Plant Sci 9: 339

Suragani M, Rasheedi S, Hasnain SE, Ehtesham NZ (2011) The translation initiation factor, PeIF5B, from Pisum sativum displays chaperone activity. Biochemical and biophysical research communications 414: 390-396

Sweetman C, Deluc LG, Cramer GR, Ford CM, Soole KL (2009) Regulation of malate metabolism in grape berry and other developing fruits. Phytochemistry 70: 1329-1344 Sweetman C, Sadras VO, Hancock RD, Soole KL, Ford CM (2014) Metabolic effects of elevated temperature on organic acid degradation in ripening Vitis vinifera fruit. J Exp Bot:

Tan BC, Schwartz SH, Zeevaart JA, McCarty DR (1997) Genetic control of abscisic acid biosynthesis in maize. Proceedings of the National Academy of Sciences 94: 1223512240

Torregrosa L, Bigard A, Doligez A, Lecourieux D, Rienth M, Luchaire N, Pieri P, Chatbanyong R, Shahood R, Farnos M, Roux C, Adiveze A, Pillet J, Sire Y, Zumstein E, Veyret M, Le Cunff L, Lecourieux F, Saurin N, Muller B, Ojeda H, Houel C, Péros J-P, This P, Pellegrino A, Romieu C (2017) Developmental, molecular and genetic studies on grapevine response to temperature open breeding strategies for adaptation to warming. OENO One 51: 155-165

Turoczy Z, Kis P, Torok K, Cserhati M, Lendvai A, Dudits D, Horvath GV (2011) Overproduction of a rice aldo-keto reductase increases oxidative and heat stress tolerance by malondialdehyde and methylglyoxal detoxification. Plant Mol Biol 75: 399412 
Usadel B, Nagel A, Thimm O, Redestig H, Blaesing OE, Palacios-Rojas N, Selbig J, Hannemann J, Piques MC, Steinhauser D, Scheible WR, Gibon Y, Morcuende R, Weicht D, Meyer S, Stitt M (2005) Extension of the visualization tool MapMan to allow statistical analysis of arrays, display of corresponding genes, and comparison with known responses. Plant Physiol 138: 1195-1204

Van Leeuwen C, Schultz HR, de Cortazar-Atauri IG, Duchêne E, Ollat N, Pieri P, Bois B, Goutouly J-P, Quénol H, Touzard J-M (2013) Why climate change will not dramatically decrease viticultural suitability in main wine-producing areas by 2050 . Proceedings of the National Academy of Sciences 110: E3051-E3052 Van Leeuwen C, Seguin G (2006) The concept of terroir in viticulture. Journal of wine research 17: 1-10

Vanderauwera S, Suzuki N, Miller G, van de Cotte B, Morsa S, Ravanat JL, Hegie A, Triantaphylides C, Shulaev V, Van Montagu MC, Van Breusegem F, Mittler R (2011) Extranuclear protection of chromosomal DNA from oxidative stress. Proceedings of the National Academy of Sciences of the United States of America 108: 1711-1716 Wahid A, Gelani S, Ashraf M, Foolad MR (2007) Heat tolerance in plants: an overview. Environmental and experimental botany 61: 199-223

Walker RP, Battistelli A, Moscatello S, Tecsi L, Leegood RC, Famiani F (2015) Phosphoenolpyruvate carboxykinase and gluconeogenesis in grape pericarp. Plant physiology and biochemistry : PPB / Societe francaise de physiologie vegetale 97: 62-69

Wang L, Sun X, Weiszmann J, Weckwerth W (2017) System-Level and Granger Network Analysis of Integrated Proteomic and Metabolomic Dynamics Identifies Key Points of Grape Berry Development at the Interface of Primary and Secondary Metabolism. Front Plant Sci 8: 1066

Wang X, Chen J, Liu C, Luo J, Yan X, Aihua A, Cai Y, Xie H, Ding X, Peng X (2018) Overexpression of a protein disulfide isomerase gene from Methanothermobacter thermautotrophicus, enhances heat stress tolerance in rice. Gene 684: 124-130

Welti R, Shah J, Li W, Li M, Chen J, Burke J, Fauconnier M-L, Chapman K, Chye M, Wang X (2007) Plant lipidomics: discerning biological function by profiling plant complex lipids using mass spectrometry. Frontiers in bioscience: a journal and virtual library 12: Wu HC, Bulgakov VP, Jinn TL (2018) Pectin Methylesterases: Cell Wall Remodeling Proteins Are Required for Plant Response to Heat Stress. Front Plant Sci 9: 1612

Xu J, Zhang B, Jiang C, Ming F (2011) RceIF5A, encoding an eukaryotic translation initiation factor $5 \mathrm{~A}$ in Rosa chinensis, can enhance thermotolerance, oxidative and osmotic stress resistance of Arabidopsis thaliana. Plant Mol Biol 75: 167-178

Yan X, Qiao H, Zhang X, Guo C, Wang M, Wang Y, Wang X (2017) Analysis of the grape (Vitis vinifera L.) thaumatin-like protein (TLP) gene family and demonstration that TLP29 contributes to disease resistance. Scientific reports 7: 4269

Yanguez E, Castro-Sanz AB, Fernandez-Bautista N, Oliveros JC, Castellano MM (2013) Analysis of genome-wide changes in the translatome of Arabidopsis seedlings subjected to heat stress. PLoS One 8: e71425

Young PR, Eyeghe-Bickong HA, du Plessis K, Alexandersson E, Jacobson DA, Coetzee Z, Deloire A, Vivier MA (2016) Grapevine plasticity in response to an altered microclimate: Sauvignon Blanc modulates specific metabolites in response to increased berry exposure. Plant physiology 170: 1235-1254

1163 Desiderio A, Lilley KS, Pe ME, Benvenuto E, Delledonne M, Pezzotti M (2010) 
1164 Identification of putative stage-specific grapevine berry biomarkers and omics data 1165 integration into networks. Plant Physiol 154: 1439-1459

1166 Zhang D, Chen L, Li D, Lv B, Chen Y, Chen J, XuejiaoYan, Liang J (2014) OsRACK1 is 1167 involved in abscisic acid- and H2O2-mediated signaling to regulate seed germination in 1168 rice (Oryza sativa, L.). PLoS One 9: e97120

1169 Zhang L, Liu X, Gaikwad K, Kou X, Wang F, Tian X, Xin M, Ni Z, Sun Q, Peng H, Vierling E 1170 (2017) Mutations in eIF5B Confer Thermosensitive and Pleiotropic Phenotypes via Translation Defects in Arabidopsis thaliana. The Plant cell 29: 1952-1969

1172 Zhao J (2015) Flavonoid transport mechanisms: how to go, and with whom. Trends in 1173 plant science 20: 576-585 
1178 Figure 1. Venn diagrams displaying the numbers of DAPs in heat-treated berries, according to

1179 the developmental stage (A) or the treatment duration (B). DAPs were selected using a 1.5 fold expression change and an adjusted $\mathrm{p}<0.05$ (with FDR correction). Only proteins identified in all three biological replicates and with a minimum of two unique peptides were considered for quantification. The detailed information of the common DAPs upon HT for each stage or for each exposure time was listed as in Supplementary Tables 1 and 2.

Figure 2. Total number of differentially abundant proteins for each MapMan main category. Category description is given on the y-axis. Numbers of down- and up-regulated proteins across the 6 experimental conditions are provided on the $\mathrm{x}$-axis for each category.

Figure 3. Metabolite profiles of Cabernet Sauvignon developing berries exposed (red line) or not

(blue line) to heat stress. Metabolites are shown in their respective metabolic pathways (sugar metabolism, glycolysis, and the TCA cycle) and their temporal profiles during berry treatment ( $\mu$ mol.g $\mathrm{g}^{-1} \mathrm{FW}$ for glucose, and fructose; and nmol.g ${ }^{-1} \mathrm{FW}$ for the others) are presented alongside. For each profile, the $\mathrm{x}$-axis shows the developing stage (G: middle-green, V: véraison and $\mathrm{R}$ : middleripening) and the stress duration (1, 7 and 14 days).

Figure 4. Correlation between the expression of proteins and mRNAs in developing control and

HT berries. DAPs and DEGs were selected using a 1.5 and 2 fold expression change, respectively, and an adjusted $\mathrm{p}<0.05$ (with FDR correction). Venn diagrams display the number of DAPs and DEGs (red: up-regulated and blue: down-regulated) according to the developing stage (A: middlegreen, B; véraison and C: middle-ripening) and the stress duration (1 and 7 days).

Figure 5. Schematic overview of heat stress effects on developing Cabernet Sauvignon berries. This illustration summarizes the main findings deduced from transcriptomic, proteomic and metabolomics analyses (this work and (Lecourieux et al. 2017)). Up and down arrows reflect the accumulation levels of the corresponding transcripts, proteins or metabolites in heated berries. 


\section{SUPPORTING INFORMATION}

1208 Figure S1: MapMan GO categories impacted at the transcriptomic and proteomic levels in heated

1209 grape berries

1210

1211 Table S1: All identified proteins with calculated differentials and corresponding statistics

1213 Table S2: List and information about the differentially abundant proteins between control and heat 1214 stress conditions

Table S3: Differentially abundant proteins between control and heat stress condition at green stage

1218 Table S4: Differentially abundant proteins between control and heat stress condition at veraison stage

Table S5: Differentially abundant proteins between control and heat stress condition at ripening stage

Table S6: List of "Protein metabolism" related DAPs

Table S7: List of "Stress" related DAPs

Table S8: List of "Secondary metabolism" related DAPs

Table S9: List of "carbohydrate and energy metabolism" related DAPs

Table S10: Effects of the HT and developmental stages on individual metabolites,

Table S11: List of overlapping DEGs and DAPs in Cabernet Sauvignon berries exposed or not to HT

Table S12: DAPs with potential role in thermotolerance. 
Table 1: Amount of identified proteins and differentially abundant proteins in control and heat berries according to the developmental stage and the stress duration

\begin{tabular}{|c|c|c|c|c|c|c|}
\hline Samples & $\begin{array}{c}\text { Total } \\
\text { protein } \\
\text { identified }\end{array}$ & $\begin{array}{l}\text { Total protein } \\
\text { quantified } \\
\text { ( } 22 \text { peptides) }\end{array}$ & Total DAPs & $\begin{array}{l}\text { Number of } \\
\text { DAPs } \\
\text { up-regulated }\end{array}$ & $\begin{array}{l}\text { Number of } \\
\text { DAPs } \\
\text { down- } \\
\text { regulated }\end{array}$ & $\begin{array}{l}\text { Number of } \\
\text { DAPs up- } \\
\text { or down- } \\
\text { regulated }\end{array}$ \\
\hline \multirow[t]{3}{*}{ All 6 conditions } & 3972 & 2279 & 592 & & & \\
\hline & & & $\rightarrow$ DAPs in 1 condition (501) & 139 & 362 & -- \\
\hline & & & $\rightarrow$ DAPs in $>1$ condition $(91)$ & 16 & 61 & 14 \\
\hline G1D & & 1633 & 39 & 11 & 28 & \\
\hline G7D & & 1263 & 108 & 14 & 94 & \\
\hline V1D & & 1580 & 148 & 70 & 78 & \\
\hline V7D & & 1054 & 83 & 49 & 34 & \\
\hline R1D & & 1244 & 238 & 38 & 200 & \\
\hline R7D & & 857 & 84 & 13 & 71 & \\
\hline
\end{tabular}


Table 2. Deregulated proteins with potential role in heat-induced berry responses

\begin{tabular}{|c|c|c|c|c|c|c|}
\hline $\begin{array}{l}\text { Functional } \\
\text { category }\end{array}$ & $\begin{array}{l}\text { Grape accession } \\
\text { number }\end{array}$ & $\begin{array}{l}\text { Putative } \\
\text { Name }\end{array}$ & Function & \multicolumn{2}{|c|}{$\begin{array}{c}\text { Related proteins - role described in } \\
\text { the literature }\end{array}$} & References \\
\hline \multicolumn{7}{|l|}{ Stress } \\
\hline & VIT_16s0050g01150 & VvHSP90 & Chaperone & AtHSP90 & Role in & \\
\hline & VIT_17s0000g07190 & VvHSP101 & & AtHSP101 & thermotolerance & Vierling, 2001; \\
\hline & VIT_18s0041g01230 & VvHSP70 & & AtHSP70 & & 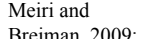 \\
\hline & VIT_04s0008g01570 & VvHSP17.6II & & AtHSP17.6II & & $\begin{array}{l}\text { Breiman, 2009; } \\
\text { Jacob et al., } \\
2017\end{array}$ \\
\hline & VIT_02s0025g04330 & VvTLP & Osmotin & Thaumatin-like & Enhance abiotic stress & Le et al., 2018 \\
\hline & VIT_02s0025g04290 & & & proteins & $\begin{array}{l}\text { tolerance in many } \\
\text { plant species }\end{array}$ & $\begin{array}{l}\text { de Jesus-Pires et } \\
\text { al., } 2019\end{array}$ \\
\hline & VIT_15s0046g01560 & VvBAG & Chaperone & AtBAG7 & Role in the unfolded & Williams et al., \\
\hline & & & & $\begin{array}{l}\text { (BCL-2-ASSOCIATED } \\
\text { ATHANOGENE 7) }\end{array}$ & $\begin{array}{l}\text { protein response } \\
\text { (UPR) to mitigate heat } \\
\text { stress }\end{array}$ & $\begin{array}{l}2010 \\
\text { Li et al., } 2017\end{array}$ \\
\hline & VIT_00s0769g00010 & VvROF1 & $\begin{array}{l}\text { Peptidyl propyl } \\
\text { isomerase }\end{array}$ & $\begin{array}{l}\text { AtROF1 } \\
\text { (AtFKBP62) }\end{array}$ & $\begin{array}{l}\text { Role in } \\
\text { thermotolerance }\end{array}$ & $\begin{array}{l}\text { Meiri \& } \\
\text { Breiman, } 2009\end{array}$ \\
\hline \multicolumn{7}{|l|}{$\begin{array}{l}\text { Protein } \\
\text { synthesis }\end{array}$} \\
\hline & VIT_14s0006g01990 & VveIF5 & $\begin{array}{l}\text { Translation initiation } \\
\text { factor }\end{array}$ & $\begin{array}{l}\text { AteIF5 } \\
\text { PseIF5 }\end{array}$ & $\begin{array}{l}\text { Role in } \\
\text { thermotolerance }\end{array}$ & $\begin{array}{l}\text { Suragami et al., } \\
\text { 2011; Zhang et } \\
\text { al., } 2017\end{array}$ \\
\hline \multicolumn{7}{|l|}{ Transport } \\
\hline & VIT_14s0108g01420 & VvCNGC2 & Cyclic nucleotide & AtCNGC2 & Primary heat sensor & Saidi et al., 2009 \\
\hline & & & gated calcium channel & AtCNGC6 & Role in & Finka et al., \\
\hline & & & & $\mathrm{PpCNGCb}$ & thermotolerance & $\begin{array}{l}2012 \\
\text { Gao et al., } 2012\end{array}$ \\
\hline \multicolumn{7}{|l|}{$\begin{array}{l}\text { Hormone } \\
\text { homeostasis }\end{array}$} \\
\hline & VIT_13s0064g00810 & VVNCED & $\begin{array}{l}\text { 9-cis-epoxycarotenoid } \\
\text { dioxygenase }\end{array}$ & & $\begin{array}{l}\text { ABA biosynthesis } \\
\text { Strigolactone } \\
\text { biosynthesis }\end{array}$ & $\begin{array}{l}\text { He et al., } 2018 \\
\text { Jia et al., } 2018\end{array}$ \\
\hline & & & & & $\begin{array}{l}\text { Role in drought } \\
\text { tolerance in grape }\end{array}$ & \\
\hline & VIT_01s0010g01840 & VvGER5 & & GEM (Glabra2 & ABA signalling & $\begin{array}{l}\text { Baron et al., } \\
\text { 2014. Bhatta et }\end{array}$ \\
\hline & & & & $\begin{array}{l}\text { Expression } \\
\text { Modulator) }\end{array}$ & pathway & al., 2018 \\
\hline & VIT_18s0072g00380 & VvASR & & VvMSA & $\begin{array}{l}\text { Responses to water } \\
\text { deficit }\end{array}$ & $\begin{array}{l}\text { Medici et al., } \\
2014\end{array}$ \\
\hline & VIT_17s0000g02750 & VvRACK1 & $\begin{array}{l}\text { Receptor for activated } \\
\text { kinase } 1\end{array}$ & & $\begin{array}{l}\text { Role in various } \\
\text { signalling pathways } \\
\text { including drought and } \\
\text { salt stress }\end{array}$ & $\begin{array}{l}\text { Islas-Flores et } \\
\text { al., } 2015\end{array}$ \\
\hline & VIT_06s0009g00260 & VvBSL & Protein phosphatase & $\begin{array}{l}\text { BRI1- } \\
\text { SUPPRESOR1 }\end{array}$ & $\begin{array}{l}\text { Role in brassinosteroid } \\
\text { signalling }\end{array}$ & $\begin{array}{l}\text { Maselli et al., } \\
\text { 2014; }\end{array}$ \\
\hline & & & & & $\begin{array}{l}\text { Role in stress } \\
\text { tolerance }\end{array}$ & Gruszka, 2018 \\
\hline \multicolumn{7}{|l|}{$\begin{array}{l}\text { Redox } \\
\text { regulation }\end{array}$} \\
\hline & $\begin{array}{l}\text { VIT_05s0049g01090 } \\
\text { VIT_19s0015g02610 }\end{array}$ & VvGST & $\begin{array}{l}\text { Glutathione S- } \\
\text { transferase }\end{array}$ & & $\begin{array}{l}\text { Role in abiotic and } \\
\text { biotic responses }\end{array}$ & $\begin{array}{l}\text { Nianiou-Obeidat } \\
\text { et al., } 2017\end{array}$ \\
\hline & VIT_07s0141g0039 & VvGR & Glutathione reductase & & Role in heat tolerance & $\begin{array}{l}\text { Khanna-Chopra } \\
\text { \& Chauhan, } \\
2015 ; \\
\text { Jegadeesan et } \\
\text { al., } 2018\end{array}$ \\
\hline & VIT_18s0122g01320 & VvCAT & Catalase & & $\begin{array}{l}\text { Role in basal } \\
\text { thermotolerance }\end{array}$ & $\begin{array}{l}\text { Vanderauwera } \\
\text { et al., } 2011\end{array}$ \\
\hline & $\begin{array}{l}\text { VIT_00s0615g00030 } \\
\text { VIT_00s0371g00050 }\end{array}$ & VvMTD & $\begin{array}{l}\text { Mannitol } \\
\text { dehydrogenase }\end{array}$ & VvMTD1 & $\begin{array}{l}\text { Resistance to abiotic } \\
\text { and biotic stress } \\
\text { Role in water-deficit } \\
\text { tolerance }\end{array}$ & $\begin{array}{l}\text { Patel \& } \\
\text { Williamson, } \\
2016 \\
\text { Conde et al., } \\
2015\end{array}$ \\
\hline & VIT_06s0004g02890 & VvPDI & $\begin{array}{l}\text { Protein-disulfide } \\
\text { isomerase } \\
\text { Chaperone }\end{array}$ & & $\begin{array}{l}\text { Role in abiotic stress } \\
\text { tolerance and } \mathrm{H}_{2} \mathrm{O}_{2} \\
\text { detoxification }\end{array}$ & $\begin{array}{l}\text { Eggert et al., } \\
2016\end{array}$ \\
\hline & VIT_07s0005g04600 & VvGSNOR & $\begin{array}{l}\text { S-nitrosoglutathione } \\
\text { reductase }\end{array}$ & AtHOT5 & $\begin{array}{l}\text { Role in } \\
\text { thermotolerance }\end{array}$ & $\begin{array}{l}\text { Gould et al., } \\
\text { 2003; Lee et al., } \\
2008\end{array}$ \\
\hline \multicolumn{7}{|l|}{$\begin{array}{l}\text { Co-factor } \\
\text { and vitamin } \\
\text { metabolism }\end{array}$} \\
\hline & VIT_09s0002g04490 & VvPDX1.2 & Pseudoenzyme & AtPDX1.2 & $\begin{array}{l}\text { Role under heat and } \\
\text { oxidative stress } \\
\text { conditions }\end{array}$ & $\begin{array}{l}\text { Moccand et al., } \\
2014 \text {; } \\
\text { Dell'Aglio et } \\
\text { al., } 2017\end{array}$ \\
\hline & VIT_01s0127g00490 & VvPANK & Pantothenate kinase & & $\begin{array}{l}\text { Induced in response to } \\
\text { salt stress }\end{array}$ & $\begin{array}{l}\text { Liu et al., 2013; } \\
\text { Aloisi et al., } \\
2016\end{array}$ \\
\hline
\end{tabular}


Figures:

A Green stage (HT vs control) Veraison stage (HT vs control) Middle ripening stage (HT vs control)
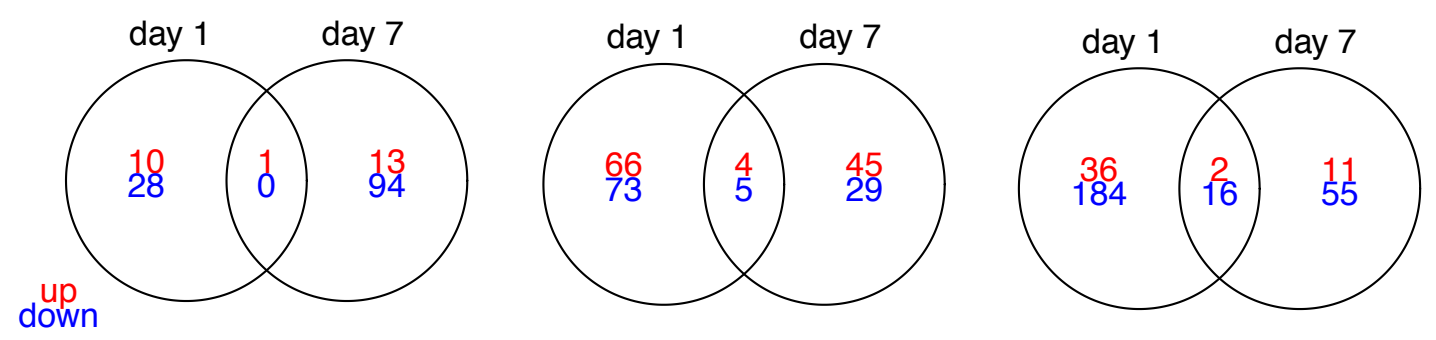

B

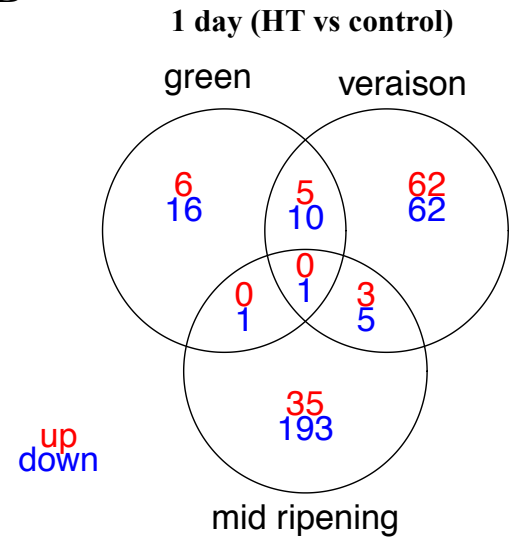

1248
7 days (HT vs control)

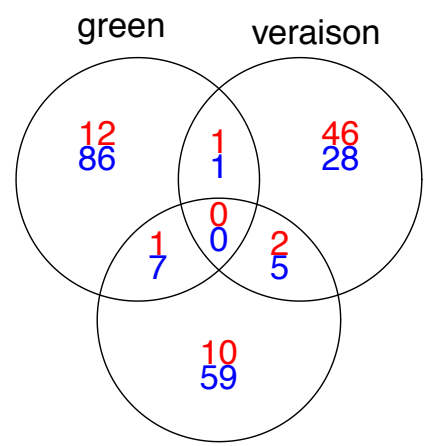

mid ripening
C HT vs control (day1 and/or day 7)

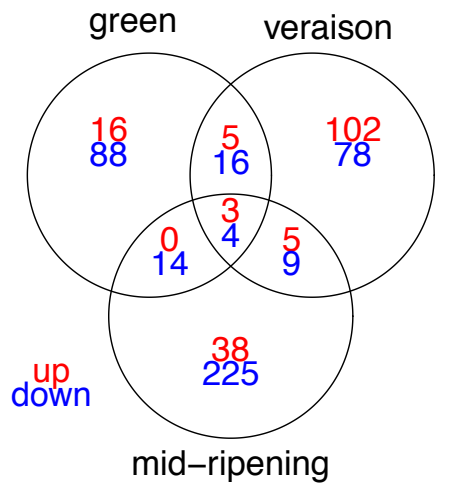

Figure 1. Venn diagrams displaying the numbers of DAPs in heat-treated berries, according to the developmental stage (A) or the treatment duration (B). DAPs were selected using a 1.5 fold expression change and an adjusted $\mathrm{p}<0.05$ (with FDR correction). Only proteins identified in all three biological replicates and with a minimum of two unique peptides were considered for quantification. The detailed information of the common DAPs upon HT for each stage or for each exposure time was listed as in Supplementary Tables 1 and 2. 


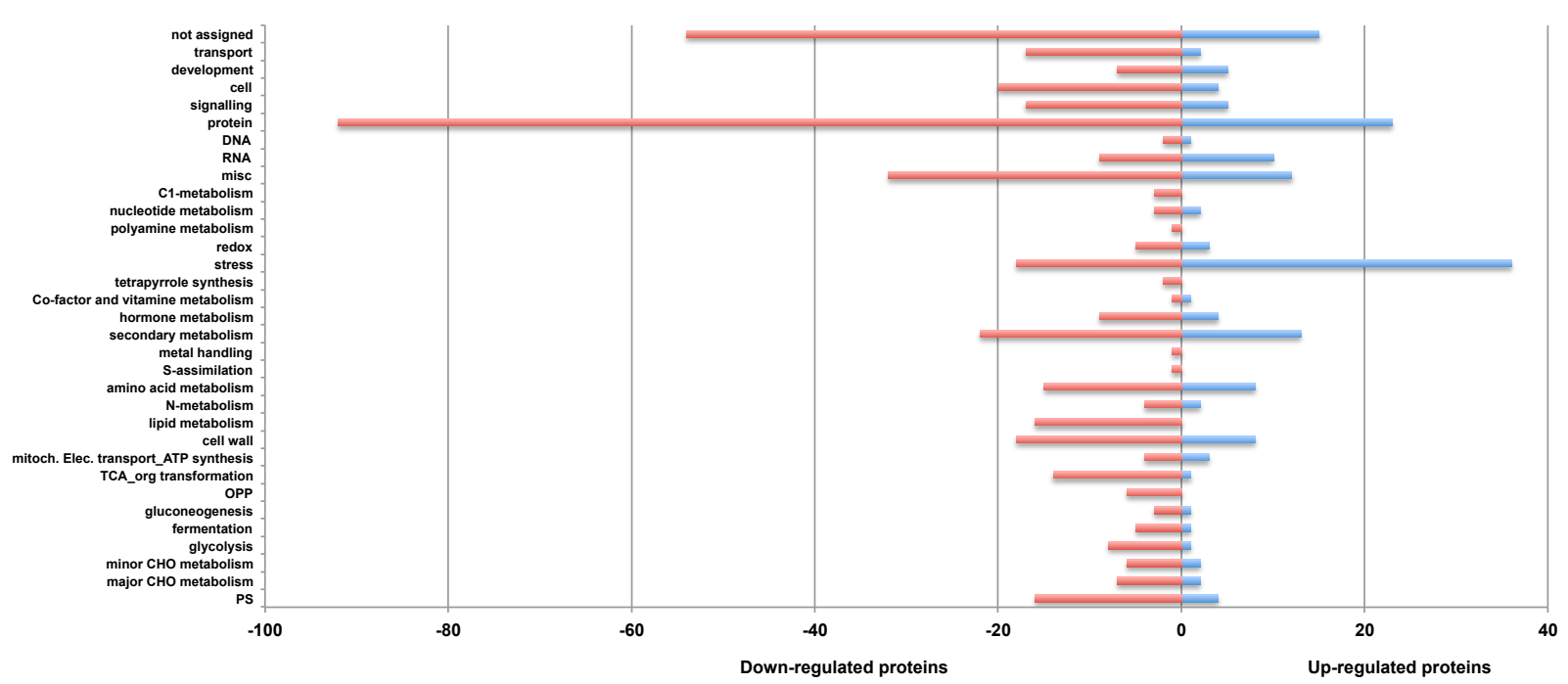

1259 Figure 2. Total number of differentially abundant proteins for each MapMan main category.

1260 Category description is given on the y-axis. Numbers of down- and up-regulated proteins across the 6 1261 experimental conditions are provided on the $\mathrm{x}$-axis for each category. 


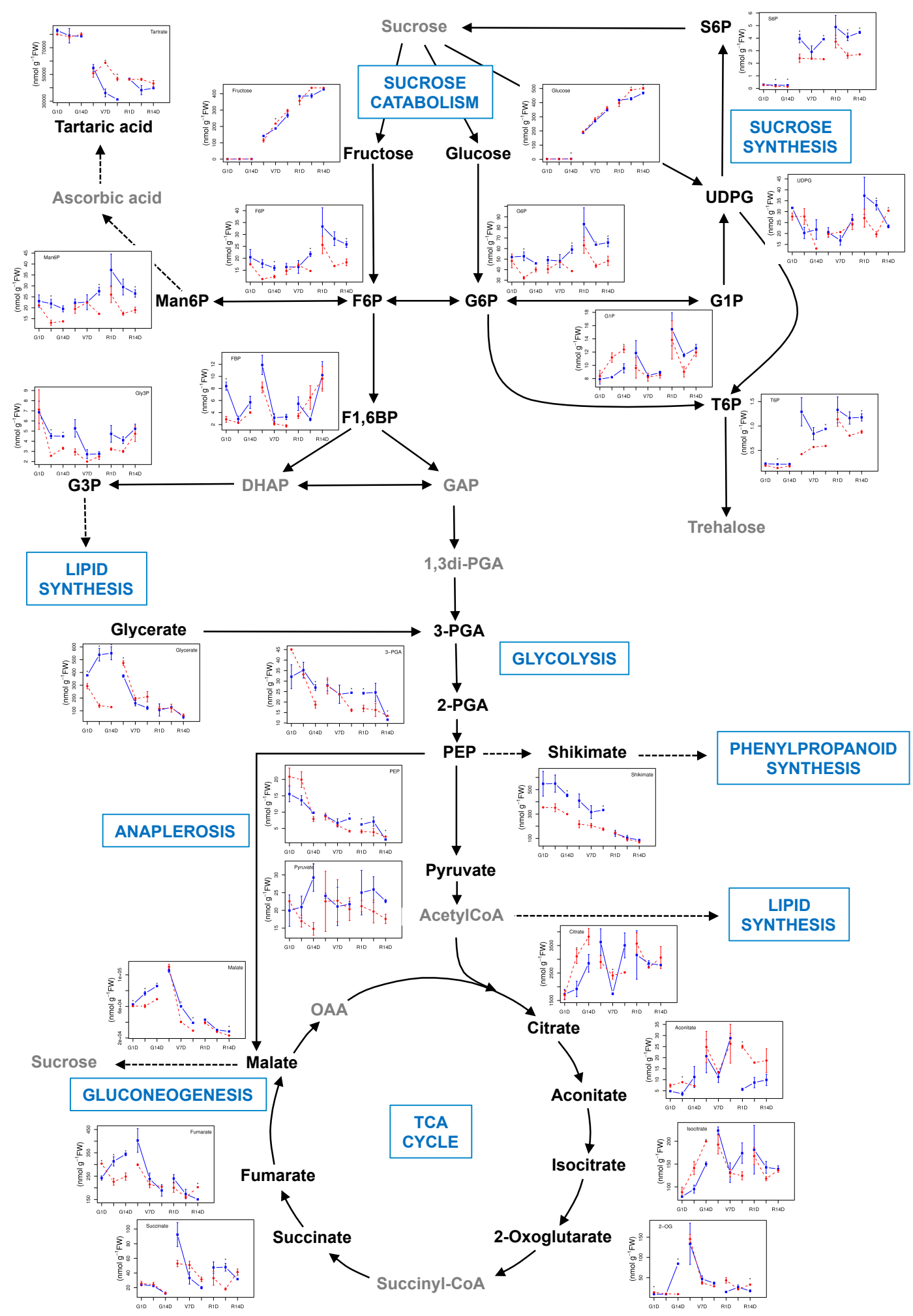

Figure 3. Metabolite profiles of Cabernet Sauvignon developing berries exposed (red line) or not

1265 (blue line) to heat stress. Metabolites are shown in their respective metabolic pathways (sugar metabolism, glycolysis, and the TCA cycle) and their temporal profiles during berry treatment ( $\mu$ mol.g $\mathrm{g}^{-1} \mathrm{FW}$ for glucose, and fructose; and nmol.g ${ }^{-1} \mathrm{FW}$ for the others) are presented alongside. For each profile, the $\mathrm{x}$-axis shows the developing stage (G: middle-green, $\mathrm{V}$ : véraison and $\mathrm{R}$ : middleripening) and the stress duration (1, 7 and 14 days). 
A

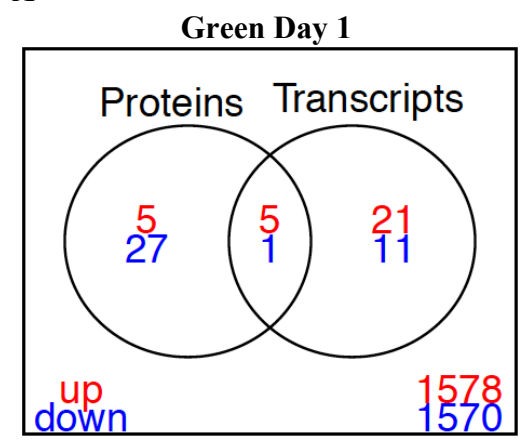

B

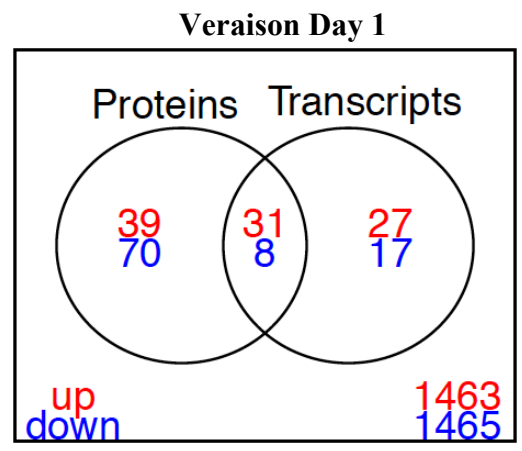

C

Ripening Day 1

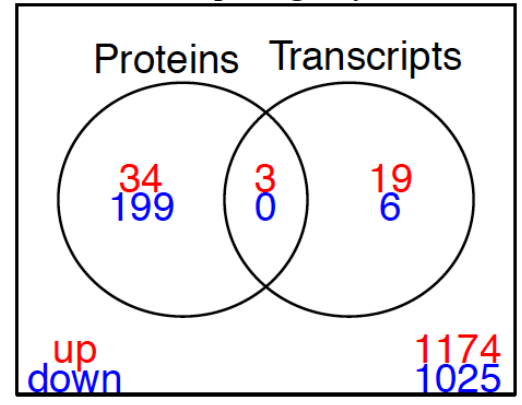

Green Day 7

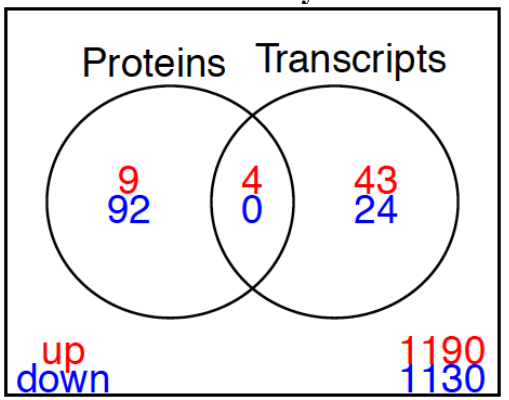

Veraison Day 7

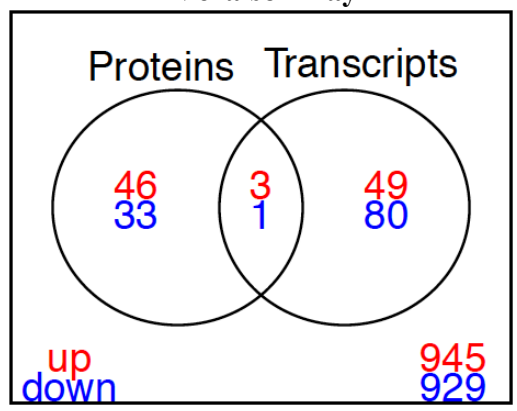

Ripening Day 7

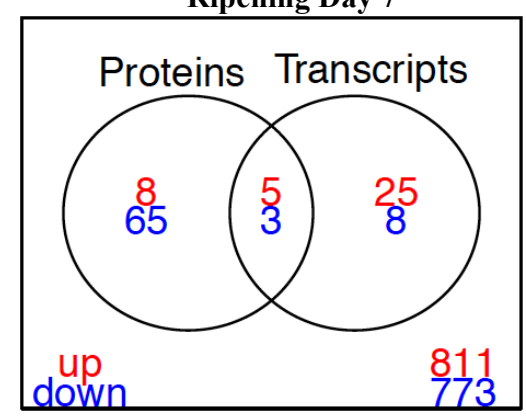

1272 Figure 4. Correlation between the expression of proteins and mRNAs in developing control and

1273 HT berries. DAPs and DEGs were selected using a 1.5 and 2 fold expression change, respectively, 1274 and an adjusted $\mathrm{p}<0.05$ (with FDR correction). Venn diagrams display the number of DAPs and 1275 DEGs (red: up-regulated and blue: down-regulated) according to the developing stage (A: middle1276 green, B; véraison and C: middle-ripening) and the stress duration (1 and 7 days). 


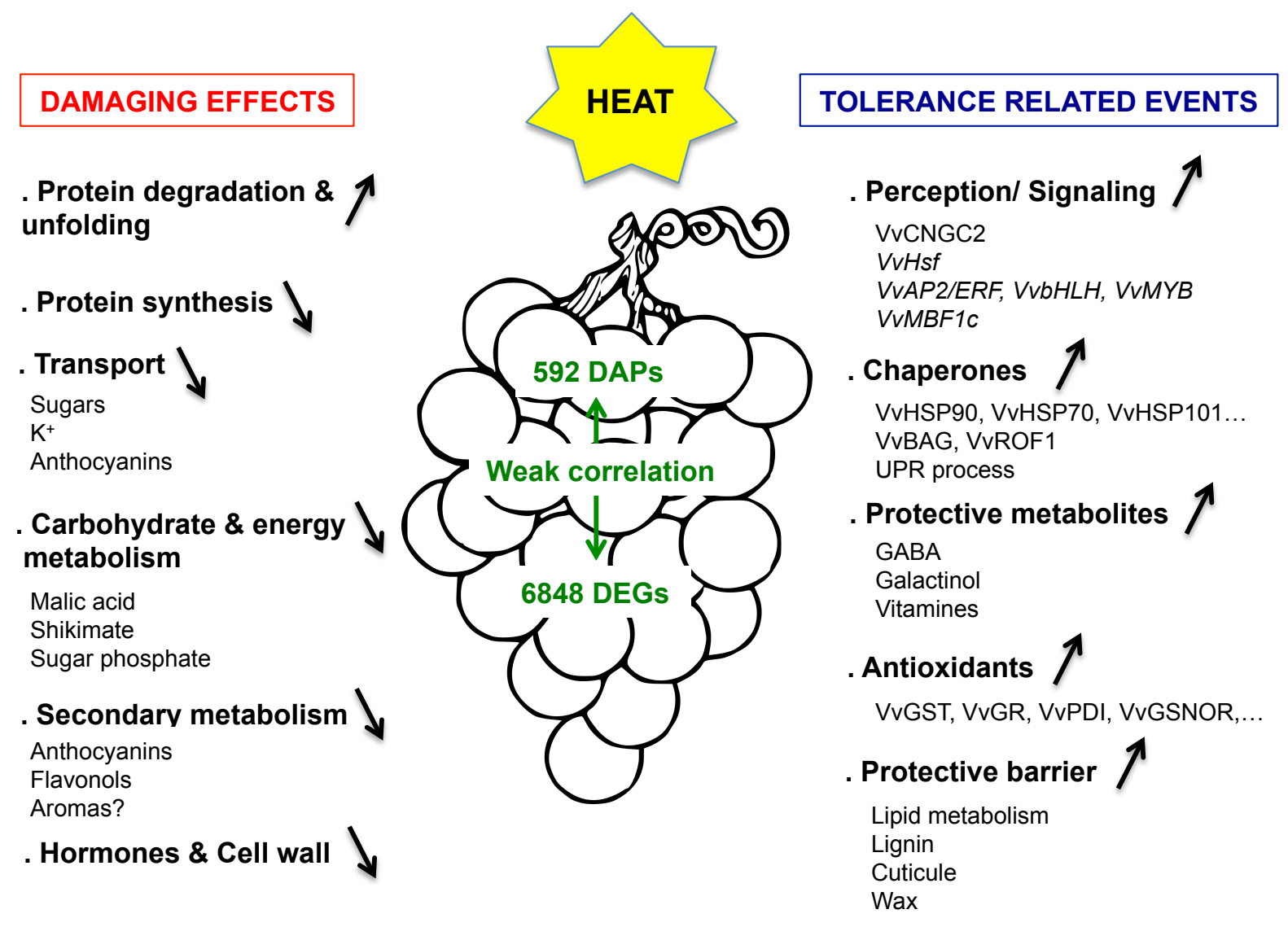

1280 Figure 5. Schematic overview of heat stress effects on developing Cabernet Sauvignon berries.

1281 This illustration summarizes the main findings deduced from transcriptomic, proteomic and 1282 metabolomics analyses (this work and (Lecourieux et al. 2017)). Up and down arrows reflect the 1283 accumulation levels of the corresponding transcripts, proteins or metabolites in heated berries. 